\title{
A Generalized Framework for the Stochastic Loss Reserving
}

\author{
by Changseob Joe Kim
}




\section{A GENERALIZED FRAMEWORK FOR THE STOCHASTIC LOSS RESERVING}

The traditional actuarial methods like loss (paid and incurred) development methods, Bornheutter-Ferguson method, or Berquist-Sherman method have been served well as long as point estimates are concerned. Since they are not stochastic approaches, they do not provide confidence intervals which are getting more attention connected to the risk-based capital requirements, explicit discounting the future liabilities, etc. So far, most of the stochastic reserving models which are either in the developing stage or are being used by some companies or organizations, have been explanatory models. The Hoerl curve fitting is their basic formulation. These types of models are fundamentally deficient, because they fit the Hoerl curve to the loss history data. Hoerl curve fitting may be fine, as long as it fits a simple, one dimensional, small series of data to obtain a fitted curve without any statistical implications. If the Hoerl curve fitting method is used with some statistical perspectives in mind, it may produce inconsistent estimtates which may not make any sense. In this article, the author suggests a generalized framework which starts by understanding the unique data characteristics of the insurance data. By expanding a Box-Jenkins type time-series model, we developed a generalized framework for modelizing a stochastic process on the loss history data. It turned out that some lines require more complex specifications than the others. We may presume that some lines are more sensitive to the insurance business cycle than the others. Our contributions will be to provide a generalized framework to derive confidence intervals in which the business cycle was taken into account as well as to provide future estimates for the planning process. This paper is the first step to that direction. 
Insurance data arranged to evaluate future liabilities takes a unique form which is different from ordinary non-insurance data. The ordinary non-insurance data usually takes a one-dimensional time-series form. For example, monthly unemployment figures for the period January 1948 - October 1977 was used to forecast November 1977 and onward monthly unemployment rate. On the while, the insurance data has to be arranged either by accident year, policy year or report year and development year in order to figure out the future liabilities of each of those years separately. Because of this, the typical insurance data takes an upper triangular form.

The traditional actuarial methods like loss (paid and incurred) development methods, Bornheutter-Ferguson method, or Berquist-Sherman method have been served well as long as point estimates are concerned. Since they are not stochastic approaches, they do not provide confidence intervals which are getting more attention connected to the risk-based capital requirements, explicit discounting the future liabilities, etc.

There have been hundreds of methods which were contended to provide confidence intervals. The fundamental problems of these methods are they are lacking in theoretical backgrounds because these methods are intended to apply to the one-dimensional data array. Minor adjustments are added to solve the problems. However, they have never been successful.

In this article, the author suggests a generalized framework which starts by understanding the unique data characteristics of the insurance data. In the next chapter, we provide the critics regarding the problems of those suggested stochastic methods. In chapter III, we articulate the characteristics of the insurance data. We also state how these characteristcs have been incorporated in the traditional actuarial methods. In chapter IV, 
the theoretical framework will be provided. We will show some applicaitons in chapter V and conclude in chapter VI.

\section{Chitics on suggested stochastic models}

Makridakis and Wheelwright (1985) suggested:

If the user wants to increase forecasting accuracy, a time series method should be used. If the objective is to understanding better the factors that influence forecasting (prediction) accuracy, then an explanatory model should be selected.

So far, most of the stochastic reserving models which are either in the developing stage or are being used by some companies or organizations, have been explanatory models. The Hoerl curve fitting is their basic formulation. First of all, the explanatory variables in their models are either the number of development years and its functional variations, the number of accident years, the number of calendar years or a combination of these. Because of these formulations, their explanatory variables do not explain the dependent variable quite well. For example, "increase one unit of log transformed development years will decrease .3 unit of total loss paid" does not provide any valuable information.

Secondly, normally it is assumed that the time series data consists of four parts of components. They are trend, seasonality, cycle and ramdom components. If we use time and its functional variation as only explanatory variables, we are ignoring the seasonal and cyclical components of data. If the annual data is used, we may ignore the seasonality, but not the cyclical component. Since some insurance business is sensitive to the business cycle, we may expect that the cyclical movement is a critical component of the data.

Thirdly, since one of the explanatory variables is a functional variation of the other, these two explanatory variables are highly correlated. This problem is called multicollinearity. If one of these two variables is deleted, there will be an autocorrelation problem because 
the remaining explanatory variables will not fully explain the dependent variable. The consequences of these problems include: unstable estimates, spurious predictions, inconsistent estimation of standard errors and confidence intervals.

Some argue that as long as the autocorrelations between the two explanatory variables are lower than that bewteen the dependent and explanatory variables, we do not have to worry about this problem. This may be true if the two explanatory variables are independently created. This is why explanatory variables are sometimes called independent variables. They are supposed to be independent. However, as long as correlations between these explanatory variables are not high compared to correlations between dependent variable and explanatory variables, the problem may not be that serious. The issue here is whether we should use models which contain multicollinearity problems due to the model formulation (one of the explanatory variables is a functional variation of another).

The other problem of these types of explanatory models is what type of indicator we should use for the accident year trends. Some authors normalized all incremental payments based on some readily available index of inflation. We cannot simply divide incremental payments by some indices, because these indices are estimated with their own variances. Consequently, it requires to assume that these indices are deterministic. However, this assumption is hardly persuasive at all. Because of this problem, some autbors divide the payments by some types of exposures. The problem of this approach is we need to find an alternative if there isn't any exposure data available, which is often the case. Still others introduce level parameters which are assigned same values to each accident years. Since the level parameters themselves have to be estimated, this automatically violate the assumption that explanatory variables are supposedly nonrandom variables which are the cases of the other two variables. Others create another explanatory variable using the sum of the accident year and the development year. They chose this as another explanatory variable because they could not use the number of accident years as their explanatory 
variable due to the perfect linearity with the number of development years. This choice is as bad as choosing the number of development years as an explanatory variable.

Still another problem of this type of model is that they do not provide any method that deals with interrelationships between series of incremental payments and incremental claims reported. Other things being equal, we expect more incremental payments if there are more claims reported. Therefore, if claims reported data is available, we should utilize these data assuming that this is also a stochastic process. So far no method has been suggested to deal with this situation. Some authors apply traditional loss development approach in obtaining ultimate claims reported. They treat them as a determinstic variable to divide incremental payments by these estimated ultimate claims reported.

What if we need to analize quarterly data instead of annual data? Quite possibly that quarterly data may contain seasonal patterns. No methods have been suggested to deal with this seasonality problem.

These types of models are fundamentally deficient, because they fit the Hoerl curve to the loss history data. Hoerl curve fitting may be fine, as long as it fits a simple, one dimensional, small series of data to obtain a fitted curve without any statistical implications. If the Hoerl curve fitting method is used with some statistical perspectives in mind, it may produce inconsistent estimtates which may not make any sense.

\section{Insurance Data as a Two-Dimensional Time-series}

\section{Data itself.}

Insurance loss or claim history data can be considered as a two dimensional time serjes data. Loss or claim development, in which additional losses or claims are paid/reported in chronological order upon accidents occurred or claims reported is one dimension. A 
chronogical order of claims grouped by date of occurence is another dimension. As a result, a typical insurance loss or claim history takes an upper triangle form. A prediction of future loss payments or claims reported corresponds to filling out the bottom lower triangle area assuming that the first accident or reported year losses or claims are fully developed.

There are at least two factors which cause loss history data as time-series through the accident years. The first factor is inflation. Ever increasing price levels (at least prior to the current recession) is called economic inflation. Increased tendency to file more claims helped by trial lawyers or increasing amount of jury awards is called social inflation. Some authors have tried to catch these inflations by either normalizing the incremental payments or by inserting a level parameter. The indices used were either general price indices or at most industry-specific indicator. Because of ever increasing tendencies of the loss payment and these general indices, you may obtain significant $t$-values for the estimated coefficient of these indices. These $t$-values are disguising. Even if you insert any series which is increasing, you may still obtain significant $t$-values. Instead of inserting or dividng by an extraneous series, we should use the data's own indices! We should look at every trend and/or cyclical pattern of incrernental payment of each development year. Interestingly, there is an approach which utilizes these trends to estimate ultimate losses. The problem is it is not a stochastic approach. We cannot obtain confidence intervals based on this approach. We will present this approach later.

As more consumers or insureds are getting more information on their insurance policy provisions, and as more trial lawyers are eagerly recruiting their clients, we can expect more claims to be reported over the accident year horizon. As overall population grows, there will be more policies written. Other things being equal, consequently there will be more claims reported. These utilization increase and additional new polcies will be the main driving force for the consistent upward trend through the accident year horizon. 
For the development horizon, since there is a fixed number of policies written during the policy effective period, there is a fixed number of occurrence of accidents for each accident year. There may be some incurred but not reported claims which are reported later. There may be some cumulative injury claims which take many years to be closed. Still every claim will be closed eventually. In a mathematical term, total cumulative loss payments or total reported claims will be converged to certain levels. Because of this characteristic, all incremental payments and all incremental reported claims will be automatically satisfied with the stability condition of the time-series analysis. This stability is a necessary condition in applying Box-Jenkins types time-series framework.

The traditional actuarial method called the "loss or claim development method ", utjlizes the development period dimension in a simple manner. The accident period dimension in this method is partially utilized by taking current cumulative payments as "given". Recently proposed regressional approaches are lacking in these two dimensional features. As in the traditional actuarial loss development (LD) method, these new methods reflect the loss development dimension by using "age" of loss development. However, the other dimension is either completely ignored or grouped together by assigning dummy variables or filled with a so-called level parameter. There is an inherent autocorrelation problem which may not be significant in some lines due to negligence of the time related features in the loss history data, especially for long tail lines in which regulators or company's executives are most interested.

In the traditional development approach, by multiplying the selected factors for each development year, some sort of time-series conception was used in a simple fashion. For instance, assuming that there are no additional payments after ten years of development, the ultimate factor for the 1982 accident year will be obtained by taking a ratio of the 10 th year development to the 9 th year of development. Notice that only the accident year 1981 and prior provides the information required to obtain a factor for the 9th to 10th 
development. The ultimate factor for 1983 is derived through multiplying the selected factor from the 8 th to 9 th year of development by the selected factor from the 9 th to 10 th year of development. Again the selected factor for 8th to 9 th year of development is based on the factors which are available in 1982 and prior accident years. Although it is a simple fashion, without a consideration of cyclical patterns, the development method reflects time series characteristic through development years. In the accident year direction, the LD method simply takes most current actual payments as selected estimates. If these values are outliers, the LD method will generate biased estimates. Otherwise, the LD method will produce reasonable estimates. For the older accident years, the actual values are fairly close to the estimates which are supposed to be compared to its maturity because the payments have already been made quite a few times (approximately more than 3 or 4 years for short tail lines). The problem is most recent immature accident years. Bornheutter-Ferguson (B-F, 1978) and Berquist-Sherman (B-S, 1979) suggested a couple of methods to get over these problems.

\section{Time-series Reflected in B-F Method.}

In the adjusted development method suggested by Bornheutter and Ferguson, a twoyear average of total payment at a particular development adjusted by the increase or decrease in the second year's exposure relative to the two-year average exposure was replaced for total payment. The ultimate factors derived in the development method is then applied to these adjusted losses. This method will correct some irregularities of the data. However, the adjustments contain too short memory (one year backward). The probability of two data points being outliers is only half of the probability of one data point being an outlier. Consequently, this does not provide appropriate remedies to correct the problem in the development method. This may be the reason why this method is seldomly used in the ordinary actuarial analysis. 
In the well-known B-F approach, the expected losses are first derived. Unpaid factors are then calculated from the ultimate development factors. The ultimate losses are estimated as the sum of total payment and indicated reserve, where indicated reserve is expected loss times the unpaid factor. Two methods are suggested to calculate the expected loss. The undiscounted loss provisions in the rates multiplied by the units of exposure

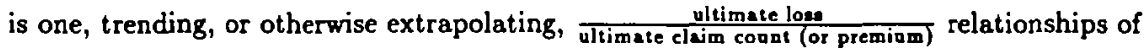
the prior accident years is the other. The author prefers the latter methods based on two reasons. First, it is very difficlut to obtain the undiscounted loss provision. One of the major reasons is the differences in line-breakdown between pricing and reserving. Second, by trending the past history, we can glean the time-series nature of the loss history data. You may notice that in LD method, only the time-series nature across the development years was recognized. By applying trending or extrapolating method to $\frac{\text { ultimate logs }}{\text { ultimate claim count }}$ across the accident years, we are able to utilize the time-series nature in another dimension at least partially (cosidering only trend factors).

This indicated (B-F) method is one of the most popular methods in the actuarial analysis because this method can be used to correct the estimated ultimate loss for the recent accident years produced by the development method.

Although these two methods are a little more advanced than loss development methods in terms of utilizing the time-series nature across the accident years, the method is not sophisticated and also performed partially (only trend factors are considered). Instead of trending a whole loss history across the accident years, only the indicated severity for each accident year was used. Since the indicated severity is also estimated, it may be contaminated with estimating errors. Berquist and Sherman suggested a few methods which utilize a whole loss history in a simple fashion.

3. Time-series Reflected in B-S Method. 
Berquist and Sherman suggested six methods ( Method I through VI) except for Method II which is exactly paid loss development method applying weighted average to loss development factors in order to obtain ultimate development factors, all methods assume that there are some trends to be utilized across the accident years. Method I applies a straight linear regression to the loss development factors for each development years as long as there are at least three factors. For columns with two factors, a straight average is taken for all future development factors. For columns which only one factor, that factor is used.

In Method III, the total payments per ultimate claim count $\left(C S_{i, j}\right)$ by accident year (i) and by development year $(j)$ are calculated. By applying a exponential fit to $C S_{i, j}$ for each $j$, a growth rate $B$; for each development year $j$ is estimated. Then by multiplying $e^{B_{i}}$ by $D S_{i, j}$ where $D S_{i, j}$ is the incremental payment for the accident year $i$ and development year $j$, we obtain a incremental payment on current cost level $I S_{i, j}$. After applying appropriate weights to these $I S_{i, j}$, the estimated incremental payments evaluated as of current date $W S_{i, m-i+1}$, where $i=m, m-1, \ldots, l$, the oldest accident year and $m$ the latest accident year are calculated. By applying growth rate $e^{B_{j}}$ to $W S_{t, m-i+1}$, future incremental payment per claim is produced. After adding them up across the development years to obtain ultimate loss per claim, ultimate loss is derived by multiplying the ultimate claim count.

In Method IV, overall growth rate is calculated by weighting various column growth rates calculated in Method III, in proportion to the square of number of rows of that column. The adjusted column growth rate is then calculated by applying the formula $B_{j}^{\prime}=\frac{W_{j} R_{j}+\left(W_{1}-W_{j}\right) R}{W_{1}}$ where $W_{j}$ is the weight for the particular column, $W_{1}$ is that for the initial colmun (development year 1 ) and $R_{j}$ is column growth rate. The same procedure with the Method III is then applied to produce the ultimate loss.

In Method V, the paid loss development factors minus unity are used instead of total 
payment per claim in Method IV to derive growth factor for the development factors. After applying the same steps as in Method IV to derive future factors (minus one), adding one to each of the results and applying resulting factors to total payments, the ultimate losses are derived. In Method VI, the incremental payments per claim are used to estimate growth rate. The exact same steps as Method IV are then used.

Notice that in the various Berquist-Sherman methods except for Method II, more emphases are levied on the trends across the accident years. In Method I and Method III, the trend factors (growth rates) are estimated by development years. Each trend factor for a particular development year is independent of those of the other development years. On the while, in the Method IV, V, and VI, the overall trend factor was calculated by the weighted average of all the trends for each development years. The adjusted trend for individual development year was then calculated as a weighted average of its own trend and the overall trend. Since these methods are focused on the time-series nature of the loss history across the accident years ignoring possible cyclical patterns, by combining the ultimate loss based on these method and the ultimate loss based on the loss development method, we can produce relatively reasonable selected ultimate loss.

As we have seen in this chapter, even if the word of time-series has never been spelled out, one way or the other, every method tried to utilize the time-series concept. The trouble was that the concept was utilized partially. Except for Berquist-Sherman methods, more weights were given to the claim development process. Even in one direction, only the trend component of the time-series was refiected. A cyclical movement and seasonal pattern were completely ignored. In our approach, the two dimensions are explicitly taken into account. Today's loss payment is not only a function of losses paid in the past loss development periods, but also a function of losses paid in the past accident periods. The implication of various statistics in the time series method are also considered in a two dimensional perspective. Empirical results based on various lines of industry total are shown. 


\section{A Framework of Two Dimensional Time Series Model}

\section{The Univariate Model.}

1) Assumptions

In this univariate model, we assume that only the payment series is available. There is no reliable case reserve, exposure or reported claim information available. More often than not, actuaries, especially consulting actuaries, have to provide ultimate loss payment based on exclusively loss payment series.

We also assume that the available data is not separable to the individual claim level. In other words, we treat the incremental payment for a particular accident period and development period itself as a random variable. This is a realistic assumption because most loss history data takes an upper triangular form in which the incremental payment is a minimum unit of counting.

We assume that the tail of the loss payment development is known. This assumption may not be realistic. However, it is at least practical. Whenever we fit any distributional curve to the loss payment developments, the estimated curve converges to the ultimate level a lot more slowly than we ever expect in actual loss developments. Unless we assume a certain cut-off point, the estimated length of the development will be extremely long.

We assume that any payment in a certain point is affected only orthognally. For example, total or incremental payment in [accident year 83 - third development year] is a function of [accident year 83 - second deveopment year] and [accident year 82 - third development year]. This is a reasonable assumption to simplify the algorithms and also consistent with the average norm. We can expect the incremental payment at [accident year 83 - third development year] will be high if the incremental payment at [accident year 83 - first and second development years] due to either volume increase or frequency/severity 
increase. Also we can expect the incremental payment at laccident year 83 - third development year] will be high if the incremental payments at [third development year - accident year 81 or 82 ] are high. The former tendency may be related to the inflation, exposure, and frequency/severity change. The latter may be related to the company's individual line characteristics - like a liability line develops more slowly than a property line.

Finally, we assume that the selected model is the true model. In others words, specification error is ignored. This error exits only in a bypothetical sense. Since in reality the true model is never known, you can never measure the direct error. This assumption is consistent with most econometric or time-series literatures. By assigning higher probability confidence intervals than what is necessary, we can eliminate the specifiaction error problem. For example, if the confidence intervals with $90 \%$ probability is required, then by raising the probability to the $95 \%$ level, we may take into consideration the specification error problem.

\section{2) Model}

Parzen suggested a very powerful time-series forecasting model. It extends the BoxJenkins methodology and provides a more practical alternative to the time-series forecasting model. Also the theoretical supports of "ARAM $A$ " models are solid and their potential contribution to good forecesting is excellent.

Contrary to the Box-Jenkins methodology, Parzen's approach is not as concerned with parsimony. Parzen's model is willing to sacrifice the parsimony that would result from introducing the moving average terms, and simply includes more autoregressive terms. The $M A$ terms are available but used only for special cases when a scheme cannot be used to produce random residuals.

We utilize Parzen's view of Box-Jenkins time-series methodology. The main reason is the tractability without giving away any theoretical merits. In our application, the 
stability may not be an important jssue. In the development period horizon, because any open claim will be closed eventually, the convergence of the time-series is guranteed. In the accident period, due to the regulation constraint of premium-surplus ratio, there exists a limit of maximum expansion. Consequently, as long as there are enough data points, we expect the stability condition will be met in the average insurance data.

Across the accident year we restrictly use $A R$ terms. However, across the development year, we first take differencing on the total payments and then take log transformation if it is possible. After transforming long memory time series across the development years, the $A R$ terms are used to produce white noise errors.

It is a matter of semantic, whether you need a differencing operation or not across the development years. If you start with incremental payment data, there is no need of differencing. However, if you start with the total payment data, you do need differencing due to the conspicuous cumulative nature of the payment data.

In a general form we can express the model as:

$$
\begin{aligned}
\left.F\left(I P_{i, j}\right)\right)= & \sum_{l, k} \phi_{l, k} F\left(I P_{i-l, j-k}\right)+e_{i, j} \quad l=0,1,2, \ldots, i-1 \\
& \text { and } k=0,1,2, \ldots, j-1 \quad \text { excluding } l=0 \quad \& \quad k=0
\end{aligned}
$$

where $F($.$) notates any functional form (most of the case log operator if it is possible,$ otherwise identity operator), IP denotes incremental payment for the accident year $i$ development year $j$. Since we assumed any non-orthogonal lag variables can be ignored, equation 4.1 can take much simpler form as:

$$
\begin{aligned}
F\left(I P_{i, j}\right)= & \sum_{l, k} \phi_{l, k} F\left(I P_{i-l, j-k}\right)+e_{i, j} \quad l=1,2, \ldots, i-1 \quad \& \quad k=0 \\
& \text { or } k=1,2, \ldots, j-1 \quad \& \quad l=0 \text { excluding } l=0 \quad \& \quad k=0
\end{aligned}
$$


Note that since no nonlinearity is invloved, we can use Ordinary Least Square Method to estimate $\phi_{l, k}$. This is a whole advantage expressing the model with $A R$ terms only. The most simple case will be:

$$
I P_{i, j}=\phi_{1,0} I P_{i-1, j}+\phi_{0,1} I P_{i, j-1}+e_{i, j}
$$

where the incremental payment for the accident $i$ - development $j$ is explained the incremental payment of the one year previous accident year and the incremental payment of the one year previous development year.

For a better understanding, an example will be followed. Say you allow two lags in each direction as explanatory variables. Then there are eight possible explanatory variables. They are [No lag in accident year(AY) - 1 lag in development year(DY)], [No $\operatorname{lag}$ in AY - 2 lag in DY], [1 lag in AY - 1 lag in DY], [1 lag in AY - $2 \log$, [2 lag in AY - 1 lag in DY], [2 lag in AY - 2 lag in DY], [1 lag in AY - no lag in DY], [2 lag in AY - no lag in DY]. Out of these eight combinations, the set of DY lag only is orthogonal to the set of AY lag only (four cases).

First of all, it does make sense modelizing the fact that the current incremental payments is explained by previous incremental payment series by accident and development year-wise because the current payment can be explained or can be a function of prior payments. Second, it does not have any multicollinearity problem because there is no functional relationship between the explanatory variables (note that accident year series are orthognal to the development series). Third, because it does not involve any nonlinearity, it is fairly easy to estimate parameters. Even we can use Lotus 1-2-3 to estimate these parameters. Fourth, most importantly, it provides a reasonable fit and also is also stable.

3) Interval Forecasts

Since the major contribution of the stochastic method in loss reserving is providing 
the confidence intervals, the variance of the forecast errers should be well defined. In order to derive the variance of the forecast errors, we first express $A R(l, k)$ process in the errorshock form by successive substitution for $\sum \phi_{l, k} I P_{i-l, j-k}$. By doing this, we can write the model in terms of current and past errors only as:

$$
I P_{i, j}=e_{i, j}+\xi_{0,1} e_{i, j-1}+\xi_{1,0} e_{i-1, j}+\xi_{1,1} e_{i-1, j-1}+\ldots
$$

The values of the parameters $\left(\xi_{0,1}, \xi_{1,0}, \xi_{1,1}, \ldots\right)$ depend upon the particular $A R(l, k)$ model and are called error learning coefficients.

The selected forecast $I P_{i, j}(g, h)$ can also be expressed using the equation 4-4 in terms of current and past errors:

$$
I P_{i, j}(g, h)=\xi_{g, h} e_{i, j}+\xi_{g+1, h} e_{i-1, j}+\xi_{g, h+1} e_{i, j-1}+\ldots
$$

As a result, the $(g, h)$ step ahead forecast error can be expressed as:

$$
e_{i, j}(g, h)=I P_{i+g, j+h}-I P_{i, j}(g, h)
$$

Again the equation 4-6 can be written as:

$$
e_{i, j}(g, h)=e_{i+g, j+h}+\xi_{1,0} e_{i+g-1, j+h}+\xi_{0,1} e_{i+g, j+h-1}+\xi_{1,1} e_{i+g-1, j+h-1}+\ldots
$$

Because the errors are independent, it follows from the equation 4-7 that $e_{i, j}(g, h)$ is an $M A(g-1, h-1)$ process. From the equation $4-7$, the forecast errors $e_{i, j}(g, h)$ have mean 0 and variance equal to

$$
V\left[e_{i, j}(g, h)\right]=E\left[e_{i, j}^{2}(g, h)\right]=\sigma_{e}^{2} \sum_{p, q=0}^{g, h} \xi_{p, q}^{2} \text { excluding }(p, g)=(g, h)
$$

Based on the model, not only can the future development year forecast be performed, but also the accident year forecast. However, since our main objective is to obtain confidence intervals for the future liabilities, we can focus on the development year horizon only.

\section{4) Some Examples}


For example, the one year ahead forecast to the development period horizon of the $A R(1,1)$ model can be expressed using equation 4-3 as:

$$
I P_{i, j+1}=\phi_{1,0} I P_{i-1, j+1}+\phi_{0,1} I P_{i, j}+e_{i, j+1}
$$

Then the equation 4-9 can be expressed as:

$$
\begin{aligned}
I P_{i, j+1}= & \phi_{1,0}\left(\phi_{1,0} I P_{i-2, j+1}+\phi_{0,1} I P_{i-1, j}+e_{i-1, j+1}\right) \\
& \phi_{0,1}\left(\phi_{1,0} I P_{i-1, j}+\phi_{0,1} I P_{i, j-1}+e_{i, j}\right)+e_{i, j+1}
\end{aligned}
$$

Since the only errors terms $e_{i-1, j+1}, e_{i, j}$ and $e_{i, j+1}$ are unkown and their variances are $\sigma_{e}^{2}$, the variace of $I P_{i, j+1}$ can be expressed as:

$$
V\left(I P_{i, j+1}\right)=\left(\phi_{1,0}^{2}+\phi_{0,1}^{2}+1\right) \sigma_{e}^{2}
$$

The two year ahead forecast to the development period will be:

$$
I P_{i, j+2}=\phi_{1,0} I P_{i-1, j+2}+\phi_{0,1} I P_{i, j+1}+e_{i, j+2}
$$

Again, the equation 4-12 can be expressed as:

$$
\begin{aligned}
I P_{1, j+2} & =\phi_{1,0}\left(\phi_{1,0} I P_{i-2, j+2}+\phi_{0,1} I P_{i-1, j+1}+e_{i-1, j+2}\right) \\
& =\phi_{0,1}\left(\phi_{1,0} I P_{i-1, j+1} \phi_{0,1} I P_{i, j}+e_{i, j+1}\right)+e_{i, j+2}
\end{aligned}
$$

By applying the equation 4-10, we can obtain a two year ahead forecast variance to the development period as:

$$
V\left(I P_{i, j+2}\right)=\left(\left(\phi_{1,0}^{2}\right)\left(\phi_{1,0}^{2}+\phi_{0,1}^{2}+1\right)+\left(\phi_{0,1}^{2}\right)\left(\phi_{1,0}^{2}+\phi_{0,1}^{2}+1\right)+1\right) o_{e}^{2}
$$

Similarly we can obtain an $n$ year ahead forecast variance to the development period by applying a inductive procedure as:

$$
V\left(I P_{i, j+n}\right)=\left(\left(\phi_{1,0}^{2}\right)\left(\frac{V\left(I P_{i, j+n-1}\right)}{\sigma_{e}^{2}}\right)+\left(\phi_{0,1}^{2}\right)\left(\frac{V\left(I P_{i, j+n-1}\right)}{\sigma_{e}^{2}}\right)+1\right) \sigma_{e}^{2}
$$


We can also apply the same inductive process to the $A R(2,1)$ or $A R(3,1)$ model. For the $A R(2,1)$ model, one year head, two year ahead and $n$ year ahead forecast variances are given as:

$$
\begin{aligned}
V\left(I P_{i, j+1}\right)= & \left(\phi_{1,0}^{2}+\phi_{0,1}^{2}+1\right) \sigma_{e}^{2} \\
V\left(I P_{i, j+2}\right)= & \left(\left(\phi_{1,0}^{2}\right)\left(\phi_{1,0}^{2}+\phi_{0,1}^{2}+1\right)+\left(\phi_{0,1}^{2}\right)\left(\phi_{1,0}^{2}+\phi_{0,1}^{2}+1\right)+\phi_{0,2}^{2}+1\right) \sigma_{e}^{2} \\
V\left(I P_{i, j+n}\right)= & \left(\left(\phi_{1,0}^{2}\right)\left(\frac{V\left(I P_{i, j+n-1}\right)}{\sigma_{e}^{2}}\right)+\left(\phi_{0,1}^{2}\right)\left(\frac{V\left(I P_{i, j+n-1}\right)}{\sigma_{e}^{2}}\right)+\right. \\
& \left.\left(\phi_{0,2}^{2}\right)\left(\frac{V\left(I P_{i, j+n-2}\right)}{\sigma_{e}^{2}}\right)+1\right) \sigma_{e}^{2}
\end{aligned}
$$

For the $A R(3,1)$ model, one year head, two year ahead, three year ahead and $n$ year ahead forecast variances are given as:

$$
\begin{aligned}
V\left(I P_{i, j+1}\right)= & \left(\phi_{1,0}^{2}+\phi_{0,1}^{2}+1\right) \sigma_{e}^{2} \\
V\left(I P_{i, j+2}\right)= & \left(\left(\phi_{1,0}^{2}\right)\left(\phi_{1,0}^{2}+\phi_{0,1}^{2}+1\right)+\left(\phi_{0,1}^{2}\right)\left(\phi_{1,0}^{2}+\phi_{0,1}^{2}+1\right)+\phi_{0,2}^{2}+1\right) \sigma_{e}^{2} \\
V\left(I P_{i, j+3}\right)= & \left(\left(\phi_{1,0}^{2}\right)\left(\frac{V\left(I P_{i, j+2}\right.}{\sigma_{e}^{2}}\right)\right)+\left(\phi_{0,1}^{2}\right)\left(\frac{V\left(I P_{i, j+2}\right.}{\sigma_{e}^{2}}\right)+ \\
& \left.\phi_{0,2}^{2}\left(\frac{V\left(I P_{i, j+1}\right.}{\sigma_{e}^{2}}\right)+\phi_{0,3}^{2}+1\right) \sigma_{e}^{2} \\
V\left(I P_{i, j+n}\right)= & \left(\left(\phi_{1,0}^{2}\right)\left(\frac{V\left(I P_{i, j+n-1}\right)}{\sigma_{e}^{2}}\right)+\left(\phi_{0,1}^{2}\right)\left(\frac{V\left(I P_{i, j+n-1}\right)}{\sigma_{e}^{2}}\right)+\right. \\
& \left.\left(\phi_{0,2}^{2}\right)\left(\frac{V\left(I P_{i, j+n-2}\right)}{\sigma_{e}^{2}}\right)\left(\phi_{0,3}^{2}\right)\left(\frac{V\left(I P_{i, j+n-3}\right)}{\sigma_{e}^{2}}\right)+1\right) \sigma_{e}^{2}
\end{aligned}
$$

If we expect any seasonality either across the development horizon or across the accident horizon or both, by inserting $\phi_{0, m}$ or $\phi_{m, 0}$ or both lags, we can take care of seasonality, where $m$ is the seasonality interval.

\section{The Multivariate Model.}

By applying either vector autoregressive model or transfer function model, we can expand the univariate model to the multivariate mode. Either closed counts development or reported counts development will be a good candidate for the right-hand side variable 
because we can presume that the claim counts will have a impact on the loss development; not vice versa. It is theoretically possible to derive the formula for the variances. However, we decided to postpone further articulation of the model due to the time constraint.

\section{Model Selection Process with Empirical Data}

\section{Statistics to be used.}

In order to find a right (or reasonable) model, we need certain criteria to identify whether the estimated errors are not correlated. Since we are going to use the $A R(l, k)$ model, we need to estimate partial autocorrelations (PCAF) of the residuals. We also use Q-statistic to verify overall randomness of errors. Since these statistics are intended to serve for the one-dimensional data, we have to apply these statistics to each accident year and development year separately. Because of this, we may have to be a little lenient when we reject the null hypothesis.

\section{1). Partial Autocorrelation.}

In practice, we never know the population values of autocorrelations and partial autocorrelation of the underlying stochastic process. Consequently, in identifying a tentative model, we must use the estimated autocorrelation and estimated partial autocorrelation to see if they are similar to those of typical models for which the parameters are known. Notice that since we do not have any $M A$ terms in our model, there is no need to calculate estimated autocorrelations. However, partial autocorrelations are calculated from a solution of the Yule-Walker equation system, expressing the partial autocorrelation as a function of the autocorrelation. We need to calculate estimated autocorrelation.

In any time series textbook, an estimate of autocorrelation $r(h)$ is defined as:

$$
r_{\Lambda}=\frac{c_{h}}{c_{0}}
$$


where $c_{h}$ defined as $c_{h}=1 / n \times \sum z_{t} z_{t+h} \quad h \geq 0$, and $c_{h}$ is the estimate of the autocovariance. For our model we can redefine this estimated autocorrelation for the development year dimension of the accident year $n$ as:

$$
r_{n, k}=\frac{c_{n, k}}{c_{n, 0}}
$$

in which $c_{n, k}=1 / m \sum_{j=1}^{m} z_{n, j} z_{n, j+k} \quad k \geq 0$ where $m$ is the number of development years. For the accident year dimension of the development year $m$, the estimated correlation can be defined as:

$$
r_{l, m}=\frac{c_{l, m}}{c_{0}}
$$

where $c_{l, m}=1 / n \sum_{i=1}^{n} z_{i, m} z_{i+l, m} l \geq 0$. And $n$ is the number of accident years.

The Yule-Walker equation is expressed as:

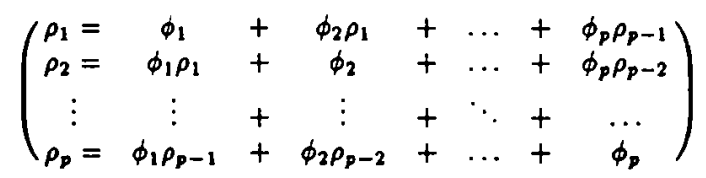

The equation 5-4 can be written as:

$$
\left(\begin{array}{ccccc}
1 & \rho_{1} & \rho_{2} & \ldots & \rho_{k-1} \\
\rho_{1} & 1 & \rho_{1} & \ldots & \rho_{k-2} \\
\vdots & \vdots & \vdots & \ddots & \vdots \\
\rho_{k-1} & \rho_{k-2} & \rho_{k-3} & \ldots & 1
\end{array}\right)\left(\begin{array}{c}
\phi_{k 1} \\
\phi_{k 2} \\
\vdots \\
\phi_{k k}
\end{array}\right)=\left(\begin{array}{c}
\rho_{1} \\
\rho_{2} \\
\vdots \\
\rho_{k}
\end{array}\right)
$$

Hence, as soon as we calculate these autocorrelation, we can derive the estimated partial autocorrelations by applying Box and Jenkins's recursive method, which are due to Durbin(1960):

$$
\begin{gathered}
\hat{\phi}_{p+1, j}=\hat{\phi}_{p, j}-\hat{\phi}_{p+1, p+1} \hat{\phi}_{p, p-j+1} \quad j=1,2, \ldots, p \\
\hat{\phi}_{p+1, p+1}=\frac{r_{p+1}-\sum_{j=1}^{p} \hat{\phi}_{p, j} r_{p+1-j}}{1-\sum_{j=1}^{p} \hat{\phi}_{p, j} r_{j}}
\end{gathered}
$$

In order to identify the exact form of the model, we need to find out when population partial autocorrelations can be considered to be zero. We therefore need to evaluate the 
standard error of the estimated partial autocollreations. Quenouille (1949) showed that the variance of the estimate of the partial autocorrelations is approximately equal to

$$
V\left(\phi_{h h}\right) \approx 1 / n, \quad h>0
$$

where $n$ equals the number of observations after suitable differencing and transformation, and $\phi$ represents the partial autocorrelations that are assumed to be zero. Equation 5.8 provides a way, after identifying the tentative model, by calcuating $\phi_{h b}$ on the estimated residuals, to evaluate if all other estimated partial sutocorrelations are different from zero. We can also define the variance of the estimate of the partial autocorrelation for the development year dimension as:

$$
V\left(\phi_{n, k t}\right) \approx 1 / m, \quad k>0
$$

and for the accident year dimension as:

$$
V\left(\phi_{l l, m}\right) \approx 1 / n, \quad l>0
$$

2). Q-test.

Box and Pierce (1970) showed that for a purely random process, that is, a model with all $\rho_{k}=0$, the statistic called Q-statistc:

$$
Q(K)=n(n+2) \sum_{k=1}^{K} \frac{1}{n-k} \hat{r}_{k}^{2} \approx \chi^{2}(K)
$$

where $\hat{r}_{k}$ is defined as

$$
\hat{r}_{k}=\frac{\sum_{t=k+1}^{n} \hat{e}_{t} \hat{e}_{t+k}}{\sum_{1}^{n} \hat{c}_{t}^{2}}
$$

with $\hat{e}$ is a fitted residual. It should be noted that the $Q$-test is not a very powerful test for detecting specific departures from white noise. However, it is useful to check how a series of autocorrelations (first order, second order and third order autocorrelations etc.) is white noise or not in an overall sense. Furthermore, the Q-test is also sensitive to the values of 
$K$, the number of autocorrelations used to calculate Q-test. For economic data, $K=12$ and $K=24$ have proven to be useful. Since insurance data have fewer data points, $K=4$ may be sufficient. Since the $\mathrm{Q}$-statistic was also designed to apply to the one dimensional data points, we performed the Q-test on each accident year and each developmemt year.

\section{Creation of Auxiliary Observations.}

We first calculate age-to-age factors for each dvelopment years. We then select ageto-age factor for each development years based on the last 5 years average method. We assume that payments of the Homeowner/Farmowners (HOMFAM), Private Passenger Automobile Liability/Medical (PRVAUT), Commercial Auto/Truck Liability/Medical (COMAUT), Commercial Multiple Peril (COMMUL), Workers' Compensation (WOKCOM), Medical Malpractice (MEDMAL), Special Liability (SPELIA), Other Liability (OTHLIA) and Product Liability (PROLIA) are paid off at 10th, 11th, 13th, 13th, 14th, 16th, 11th, 15 th and 16 th years of development, respectively. With this tail-factor assumption we create future incremental payments based on the LD method. In other words, we fill out the lower part of triangles.

There are two purposes in creating these auxiliary observations. The first purpose is creating initial values of lag variables based on the backward forecasting. Since we started with small amount of data points, we cannot afford to lose any data elements by the intializing process. By running Oridnary Least Squares with logarithms of incremental payments as dependent variables and development years for each accident year as explanatory variables, we were able to create development year initial lag values. For the accident year initial lag values we ran OLS on accident years for each development years. The second purpose was to obtain tentative models. We did not attempt to use upper triangle angle only because the model utilize the whole data at once, this will put too much emphasis on the earlier years which contain more data points. This is a major disadvantage of any stochastic model which fits the entire data at once without filling up the lower triangle 
portion. Even though the development method does not provide confidence intervals, it does provide at least an approximate estimate. It is also consistent with the NAIC model act for the liability discount which explicitly specifies the future payout patterns.

\section{Model Selection.}

We started with $A R(1,1)$ model for all nine lines we used for this analysis. Estimated coefficients are listed in Table 1. Estimated Q-test on the residuals by accident year and by development years are listed in Table 2. Due to small data points, we only estimated up to four years. Estimated partial autocorrelations on the residuals by accident year and development year are shown in Table 3. The thresholds with $95 \%$ confidence level for Q-tests are 7.81 with $K=3,9.49$ with $K=4,11.1$ with $K=5$ and 12.6 with $K=6,14.1$ with $K=7$. Most of the cases, Q-tests do not reject the Null Hypothesis that the errors are not white noise. Applying the $\frac{1}{n^{1 / 2}}$ formula, the thresholds with $95 \%$ confidence level for PCAF are 0.653 with $n=9,0.693$ with $n=8,0.741$ with $n=7$ and 0.800 with $n=6$. Except for few cases, there aren't any such cases that reject the whiteness of the errors.

Identifying a model as $A R(1,1)$ is equivalent to saying that the loss history can be explained as a combination of constant trends through accident period and development period. Since the coefficients of all lines are less than 1, we can say that data satisfies the stability condition. This is a desirable condition, otherwise, the estimated variances will be blown up. You may also notice that in every case, the coefficents for the accident year are a lot higher than those of development years. This indicates that the trends through the accident periods are much more important than those through the development years.

You may want to stop here because all the PACF are satisfactory and because the parsimony dictates the fewer the coefficients are, the better the model is. However, since the model with more coefficients will provide more stable forecastings, we tried up to $A R(3,2)$. Except for COMMUL, since the coefficients for development years are already 
small, we didn't bother to try more development lag coefficients except COMMUL. When we tried $A R(3,2)$ for COMMUL, the second development lag term became very close to the zero. Hence we selected the $A R(3,1)$ for COMMUL. The second lag term indicates that there are more than just straight trend. We may interpret this as a simple cycle. If we require a third lag term, this will indicate that the data contains a complicate cycle.

When we tried $A R(2,1)$ for HOMFAM, suprisingly the second lag term for the accident year became bigger than the first term. Consequently, we tried $A R(3,1)$. Even though the coefficient for the third lag term is still high, we decided to stop here due to the limitation of the data points. We also didn't want those artificially generated initial values to dominate the whole actual data.

For PRVAUT, we tried up to $A R(3,1)$. Since the third lag term of accident years wasn't big enough, we decided to go with $A R(2,1)$. The same was true for PROLIA. For COMAUT as soon as we tried $A R(2,1)$ the second lag became relatively small. Hence, we selected $A R(1,1)$ for COMAUT. The same was true for MEDMAL, SPELIA. For WOKCOM, as soon as we added one more lag term, the first lag term became bigger than 1.0 (which became unstable). Consequently, we chose $A R(1,1)$ for WOKCOM. Finally, for OTHLIA, we chose $A R(3,1)$ as a selected model as HOMFAM. Interestingly, the coefficent of the third lag term was highest. We showed estimated coefficients of the $A R(2,1)$ models, their Q-statistics and PCAFs on the residuals in Table 4, 5 and 6, respectively. Estimated coefficents of the $A R(3,1)$ models, their $\mathrm{Q}$-statistics and PCAFs on the residuals are shown in Table 7, 8 and 9, respectively.

As you may noticed, the process of personal lines like HOMFAM and PRVAUT ar either more complicated or as complicated as comercial lines. Secondly, the longer tail lines like MEDMAL do not necessarily possess a more complicated process.

\section{Point Estimates and Confldence Intervals.}


After we selected each model based on the rectangular form of data, we eliminated auxiliary observations in the lower triangular area. We filled the lower triangle with forcast values. By adding up row-wise we obtained ultimate loss based on the selected model. Based on the variance formula mentioned on the prior chapter, we estimated each variance for the forecast value.

In Table 10, in the first column, the upper limit of the estimated ultimate loss with 95\% probability (one-tail test) are shown. This indicates that if we repeatedly estimate the ultimate loss with different samples, but with same formula, and in each case we construct confidence intervals, then $95 \%$ of all the cases of the interval given will inclcude the true parameter. Thus, the probability statement is not about population parameter but estimated parameter.

The distance of the interval is determined by the size of the estimated variance for the error, the complexity of the model and the size of the tail. In the third column the relative distance of the confidence interval in terms of the ultimate loss are provided. In the fifth and seventh column, the upper limit of the estimated future expected liability and its relative distance of the confidence interval are shown, respectively.

If we look at the relative size of the confidence interval in terms of ultimate loss, personal lines' (HOMFAM and PRVAUT) sizes are a lot smaller than commercial lines'. Among the commercial lines, WOKCOM's relative size of the confidence interval is the smallest even though its tail is longer than either COMAUT, COMMUL or SPELIA. The WOKCOM's relative size of the confidence interval may be the smallest because its stability of the exposure growth as well as as its stable payment pattern. SPELIA's relative size of the confidence interval is bigger than either COMAUT or COMMUL or WOKCOM, even though its tail is the shortest among the commercial lines. As we expected, MEDMAL's relative size is biggest among all lines, despite of its simplicity of the model. HOMFAM and SPELIA's relative size of the confidence interval in terms of the future liability are 
extremely high compared to their size in terms of ultimate loss due to their large estimated variance of the error terms. Other lines' relative size are consistent with their counterparts.

Except for the cases of COMMUL and SPELIA whose estimated constant coefficients' signs are negative, all point estimates based on the models are slightly smaller than those based on the loss development methods. This does not necesarily indicate that modelcreated estimates are understated. One of the evidences are shown column (9) through column (13). We reserved column (9) of actual paid loss as of $12 / 91$ for the comparison purpose. In column (10), we provided the estimated paid loss as of $12 / 91$ based on the models and in column (11) the projected paid loss as of 12/91 are shown based on the development method. The performances of five lines out of nine lines were better with the models rather than the loss development methods. To the contrary of the ultimate loss comparison cases, where seven out of nine cases, the model estimates were bigger than the actuals. While five out nine cases, the estimates of loss development methods were bigger than the actuals.

One of the main advantages of our model is that it provide future estimates for the future accident years with confidence intervals. Neither ordinary regressional models nor loss development methods provide these estimates, which are valuable for planning purposes. The last rows of column (10) are future accident year estimates and their confidence intervals. Compared to the actual values in column (9), the estimates seem to be reasonable.

By looking at columns (1) through (4), you may notice that every case, the ultimate losses based on the development method has fallen inside of the confidence intervals. This is a small evidence showing that our estimated confidence intervals are reasonable. However, figures on lower rows of the columns (9) and (10) indicate that one out of nine cases, the actual payment located outside the confidence interval with a probability of $97.5 \%$, and two out of nine cases the actual payments laying outside the confidence interval with the 
probability of $95 \%$. These appear to show that our confidence intervals for the accident year may be too narrow because the actual probabilities indicate that $77.8 \%$ and $88.9 \%$ instead of the theoretical values of $95 \%$ and $97.5 \%$, respectively. This is not the case because the confidence interval with $95 \%$ probability means that there is a $95 \%$ chance that the interval includes the true parameter (true mean) not the actual value. Consequently, the $77.8 \%$ and $88.9 \%$ regarding the actual values are reasonable considering that the population possesses its own distribution. This is the main reason why the theoretical probability with the normality assumption was larger than the empirical one in Gardner (1988).

In Table 11, the actual cumulative payment triangles, age-to-age factors and ultimate losses based on the loss development methods are shown.

\section{CONCLUSION}

By expanding a Box-Jenkins type time-series model, we developed a generalized framework for modelizing a stochastic process on the loss history data. It turned out that some lines require more complex specifications than the others. We may presume that some lines are more sensitive to the insurance business cycle than the others. Our contributions will be to provide a generalized framework to derive confidence intervals in which the business cycle was taken into account as well as to provide future estimates for the planning process. This paper is the first step to that direction.

We would like to incorporate claim count estimates into our framework by utilizing vector autoregressive model in the near future. We may also incorporate outstanding reserve which is also a valuable information. 


\section{BIBLIOGRAPHY}

Berquist, J. R. and Sherman, R. E., "Loss Reserve Adequacy Testing: A Comprehensive, Systematic Approach," PCAS LXIV, 1977, p. 123.

Bornheutter, R. L. and Ferguson, R. E., "The Actuary and IBNR," PCAS LXI, 1972 p. 181.

Box, G. E. P. and Jenkins, G. M., Time Series Analysis: Forecasting and Control, 1976.

Box, G. E. P. and Pierce, D. A., "Distribution of Residual Autocorrelations in Autoregressive Integrated Moving Average Time Series Models" Journal of the American Statistical Association, 65998, p. 1509.

Durbin, J., "The Fitting of Time Series Models," Review of the International Institute of Statistic, 28, 9, p. 233.

Gardner, Jr., E. S., "A Simple Method of Computing Prediction Intervals fro Time Series Forecasts," Management Science, 94, 4, p. 541.

Maddale, G. S., Econometrics, 1977.

Makridakis, S. and Wheelwright, S. C., Forecasting Methods for Management (Fifth Edition), 1989.

Quenouille, M. H., "Approximate Tests of Correlation in Time Series," Journal of the Royal Statistical Society, Series B, 11, 1, p. 68.

Vandaele, W., Applied Time Series and Box-Jenkins Models, 1983. 
JABLE 1. ESITMATEO COEFFICEHTS FOR AR $(1,1)$ MOOEL

\begin{tabular}{|c|c|c|c|}
\hline & $\begin{array}{l}\text { 15T YEAR } \\
\text { AY LAG }\end{array}$ & $\begin{array}{l}\text { 15I YEAR } \\
\text { or TAG }\end{array}$ & COWST \\
\hline HONFM & 0.85250 & 0.13496 & 0.11621 \\
\hline PRVAUT & 0.99250 & 0.00708 & 0.11526 \\
\hline conesur & 0.98074 & 0.01818 & 0.09425 \\
\hline convit & 0.73432 & 0.27660 & -0.21894 \\
\hline $\operatorname{cox} c 00$ & 0.99844 & 0.00328 & 0.09810 \\
\hline MEDMLL & 0.85550 & 0.14628 & -0.07682 \\
\hline ormLia & 0.97503 & 0.02465 & 0.11304 \\
\hline SPELIA & 0.97018 & 0.02990 & 0.10406 \\
\hline PROLIA & 0.97063 & 0.03365 & 0.06065 \\
\hline
\end{tabular}


tABLE 2. ESITMTED O-STATISTICS OF THE RESIDUALS FOR AR(1,1) MOOEL

$K=3 \quad K=4 \quad K=5 \quad K=6 \quad K=7$

HOAFNA $2.387782 .68698 \quad 5.43216 \quad 6.60956 \quad 7.67962$ $\begin{array}{lllllll}\text { PRVAUT } & 6.20165 & 7.63330 & 0.03333 & 0.57428 & 10.27192\end{array}$ conwt B.02664 9.0896612 .7811622 .7066727 .7364 COONL 15.59455 18.74024 21.7702026 .2016426 .17824 woxcen 17.29664 26.02996 24.85543 $32.13953 \quad 34.81509$ KEOMAL $3.63636 \quad 6.52361 \quad 9.18822 \quad 13.88173 \quad 16.61208$ OTHLIA $\quad 4.38933 \quad 6.13802 \quad 6.52584 \quad 6.80700 \quad 6.81674$ $\begin{array}{llllllll}\text { SPELIA } 2.00036 & 2.33159 & 3.48908 & 3.51597 & 3.51782\end{array}$ PROLIA 10.6347711 .3550611 .4775611 .5216911 .52889

$$
\text { ACC IOENT YEAR - } 83
$$

$K=3 \quad K=6 \quad K=5 \quad K=6$

$\begin{array}{lllll}\text { HONFAM } & 2.56875 & 2.76390 & 2.93312 & 3.76685\end{array}$

PRVAUT $3.19666 \quad 4.15370 \quad 6.68083 \quad 5.11533$

conit $5.96915 \quad 7.45070 \quad 7.67292 \quad 23.55856$

coull 9.2812112 .0360016 .6166217 .97051

woxcon $7.81576 \quad 16.92529 \quad 16.12265 \quad 17.08352$

MEDMAL $20.2233525 .65722 \quad 30.6584639 .76625$

OrMLIA $7.81660 \quad 7.94727 \quad 10.03090 \quad 10.87100$

SPELIA $1.58167 \quad 2.12018 \quad 3.56677 \quad 3.96429$

Prolit $9.9544316 .92331 \quad 16.61628 \quad 21.73013$

$$
\begin{aligned}
& \text { ACCIDEMT YEAR = 86 ACCIDEHT TEAR = 85 } \\
& K=3 \quad K=4 \quad K=5 \quad k=3 \quad K=4
\end{aligned}
$$

HONFAM $1.50912 \quad 1.84325 \quad 2.69574 \quad 12.4470714 .18820$ PRVAUT $0.90452 \quad 1.73380 \quad 3.31919 \quad 8.57997 \quad 8.92221$ conuut 11.8548398 .0280119 .3591023 .7315830 .68252 Comul 19.31621 19.80737 20.31336 15.62485 17.12087 woxcon $15.00407 \quad 16.4611916 .83647 \quad 5.96221 \quad 6.27586$ MEDMAL $1.52935 \quad 2.59651 \quad 13.90429 \quad 1.81445 \quad 2.17930$ OTHLIA $7.64905 \quad 0.13170 \quad 9.67102 \quad 12.04123 \quad 17.40440$ SPELLA 8.21914 10.03992 23.363014 .133764 .18365 PROLIA $19.2310026 .0514733 .40982 \quad 9.7208411 .05814$ 
TABLE 2. ESTIMATEO O.STATISTICS OF THE RESIOUALS FOR AR(1, 1 ) MOOEL DEVELOPMENT YEAR * 1

$K=3 \quad K=6 \quad K=5 \quad K=6 \quad K=7$

HONFAM 20.86283 27.43541 29.97995 39.1603744 .28323 PRVANT 16.6526326 .2738331 .3274736 .3163638 .33991 Convit 10.11426 14.08209 19.90366 35.0981839 .43675 COML $17.3861026 .2446529 .21483 \quad 32.8572836 .79327$ voxcon 13.65747 21.10487 22.1829026.1296924.29261 MEDiul $9.0725611 .65357 \quad 12.1645112 .4395112 .53369$ OTHLIA 16.1322917 .9869823 .6536526 .5726328 .50565 SPELIA 8.23842 $8.89819 \quad 9.60571 \quad 10.4063510 .66272$ PHOLiA 10.28875 11.52355 12.65665 16.36266 16.92516

$$
\begin{aligned}
& \text { OEVELDPMEMT YEAR }=2 \\
& K=3 \quad K=4 \quad K=5 \quad K=6
\end{aligned}
$$

HOMFAN 15.8041617 .0243324 .9209234 .06265 PRVAUT 16.36262 16.4118319 .3708926 .11920 convt 9.5070311 .7565716 .5792722 .44170 convl 11.9003515 .5538316 .7886030 .58926 varcen $10.0467018 .9985922 .83892 \quad 25.65263$ KEDML 17.3561122 .3585524 .5394026 .06088 OTMLIA 14.2031615 .7202216 .7206416 .99232 SPELIA 24.36332 30.1212436 .3016838 .53166 PRollA $9.3514413 .1614713 .46168 \quad 13.71009$

$$
\begin{aligned}
& \text { DEVELOPNET YEAR = } 3 \text { DEVELOPNENT YEAR = } 4 \\
& \mathrm{k}=3 \mathrm{~K}=4 \quad \mathrm{k}=5 \quad \mathrm{k}=3 \quad \mathrm{k}=6
\end{aligned}
$$

HONFNM $12.64103 \quad 13.35973 \quad 13.69182 \quad 6.18684 \quad 7.02828$ PRVAUT 11.4216913 .9288919 .6974813 .3546215 .11712 $\begin{array}{lllllll}\text { conut } 10.18653 & 12.17216 & 17.63906 & 0.03854 & 10.13738\end{array}$ convt 14.08152 $16.70407 \quad 17.94627 \quad 10.9555613 .88691$

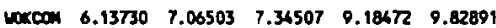
MEOML $5.6653412 .2060214 .21097 \quad 5.38701 \quad 7.75356$ OrML1A 14.29285 $22.4035527,73785 \quad 10.0627914 .94903$ SPELIA 10.25537 21.90S69 $27.88511 \quad 6.281316 .59398$ ProliA 15.05529 17.17875 18.72070 7.2077 8.26060 
TABLE 3. PCAF OF THE ESTIMATED RESIOUALS fon AR(1,1) woOEL

RESIDUAL PARTIAL AUTOCORRELATIONS FOR AY 82

RESIOUAL PARTIAL AUTOCOREELATIONS FOA AY QJ ISI LAG 21D LAG JRD LAG GTH LAG STH LAG GTK LAG IST LAG 2ND LAG 3RD LAG LTH LAG STH LAG

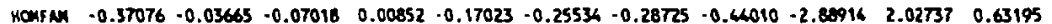
PRVAUT $-0.34487 \cdot 0.00364 \cdot 0.00112 \cdot 0.00223 \quad 0.00111 \quad 0.00201 \cdot 0.37356 \cdot 0.01520 \cdot 0.00476 \cdot 0.01134 \cdot 0.00362$ conut $-0.10285 \quad 0.00115 \cdot 0.00226 \cdot 0.00255 \cdot 0.00431 \cdot 0.00255 \cdot 0.30156 \quad 0.00355-0.00414 \cdot 0.01290 \cdot 0.00372$ comul $0.09516 \cdot-0.01340 \cdot 0.00179 \cdot 0.00324 \cdot 0.00126 \cdot 0.00043 \cdot 0.43576 \quad 0.00571 \cdot 0.00843 \cdot 0.00719 \cdot 0.02689$ $\begin{array}{llllllllllllllll}\text { woxed } & 0.16951 & 0.00092 & -0.00934 & -0.00782 & -0.00939 & -0.00908 & 0.12489 & 0.00460 & -0.01047 & -0.01656 & -0.00316\end{array}$ MEOML $-0.16126-0.10140-0.11312-0.12656 \quad 0.02052 \quad 0.00722 \quad 0.15256 \cdot 0.27062-0.19031 \cdot 0.04040 \cdot 0.09085$

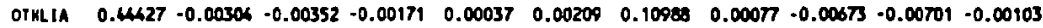
SPELIA $-0.22590-0.03193-0.00833-0.01076-0.06616 \cdot 0.00522+0.12508-0.07590-0.07512-0.11286-0.28870$

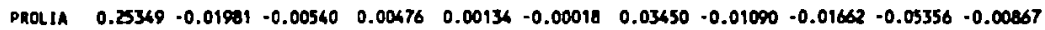

HONFAM $\cdot 0.18333 \cdot 0.02987 \cdot 0.04104 \cdot 0.05068 \quad 0.08708 \cdot 0.17562 \cdot 0.17577 \cdot 0.12642 \quad 0.07477 \quad 0.01706 \cdot 0.04708$ $\begin{array}{llllllllllllllllllll}\text { PRVAUT } & -0.02935 & 0.00670 & -0.00169 & -0.00649 & -0.00482 & -0.01315 & 0.02938 & -0.00062 & -0.00216 & 0.00043 & 0.00000\end{array}$ $\begin{array}{llllllllllllllllllllllll}\text { cont } & -0.47491 & -0.00447 & 0.00382 & -0.00309 & -0.00181 & 0.00121 & -0.46176 & -0.00270 & 0.00132 & -0.00348 & 0.00029\end{array}$ conill $\quad 0.25051 \cdot 0.01295 \cdot 0.01081 \cdot 0.00404 \cdot 0.00315 \cdot 0.00162 \quad 0.06822 \quad 0.00182 \cdot 0.00738 \cdot 0.00228 \cdot 0.00159$ soxcon $0.36364 \cdot 0.01617 \cdot 0.00186-0.02261-0.04645 \cdot 0.00271 \cdot 0.02170 \cdot 0.05033-0.11816 \cdot 0.05752-0.21919$

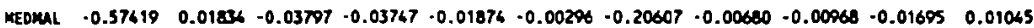
otmL1A $0.30091 \cdot 0.00597 \cdot 0.00290 \quad 0.00018 \quad 0.00095 \cdot 0.00036 \cdot 0.46420 \cdot 0.00020 \cdot 0.00140 \cdot 0.00011 \cdot 0.00003$

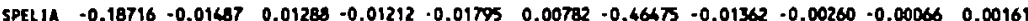
$\begin{array}{llllllllllllllllll}\text { PRoL 1A } & -0.70515 & 0.00668 & -0.02610 & -0.00267 & -0.00430 & -0.01450 & 0.02055 & -0.00099 & -0.02622 & 0.00490 & -0.02458\end{array}$ 1ST LAG 2NO LAG 3RD LAG GTM LAG STH LAG GTH LAG IST LAG 2ND LAG 3RO LAG GTH LAG STM LAG

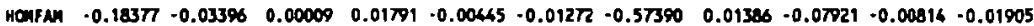
PRvaun $-0.65166-0.00008-0.00018 \quad 0.00010-0.00002 \quad 0.00003 \quad 0.25633 \quad 0.00027-0.00065-0.00004-0.00105$ $\begin{array}{lllllllllllllll}\text { conut } & -0.21997 & -0.02538 & -0.00589 & 0.01806 & 0.00802 & -0.01858 & -0.11645 & 0.01353 & -0.01616 & -0.00926 & -0.01754\end{array}$

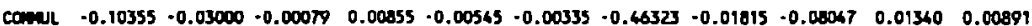
voxed $-0.35143 \cdot 0.09390-0.37586 \cdot 0.77609-1.58962 \quad 2.35511 \quad 0.06069 \cdot 0.02385 \cdot 0.01581 \cdot 0.00568-0.00437$

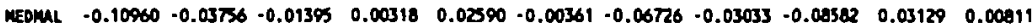
OTHLIA $-0.13521 \cdot-0.01166 \cdot-0.00083 \quad 0.00683 \cdot 0.00041-0.00166-0.03812-0.00776 \cdot 0.00575 \quad 0.00938-0.00156$

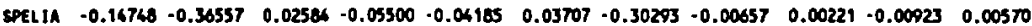
Proula $\cdot 0.46299 \cdot 0.22662 \quad 0.00621 \cdot 0.01529 \cdot 0.06378 \quad 0.00849 \cdot 0.20689 \cdot 0.00140 \cdot 0.06373 \cdot 0.03099 \quad 0.02172$

GTH LAS

0.04257

$-0.00061$

0.00189

0.05630

0.00722

0.01127

$-0.00708$

0.00422

0.00733

RESIOUAL PARTIAL AUTOCORELATIOAS FOR OY 3

RESIDUAL PARTIAL AUTOCOARELATIOHS FOA OY 4

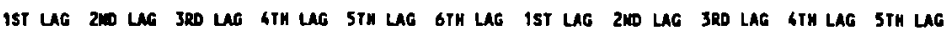


TABLE 4. ESTIMATED COEFFICENTS FOR AR( 2,1$)$ MOOEL

\section{ST YEAR ZWO YEAR IST TEAR}

$$
\text { AY LAG AY LAG OY LAG CONST }
$$

$\begin{array}{lllll}\text { HONF NH } & 0.30030 & 0.63392 & 0.06093 & 0.13195\end{array}$ PRVAUT $0.55930 \quad 0.44051 \quad 0.00025 \quad 0.17295$

$\begin{array}{llllll}\text { conuur } & 0.96540 & 0.01553 & 0.01800 & 0.09608\end{array}$

$\begin{array}{llllll}\text { combl } & 0.53940 & 0.20832 & 0.26344 & 0.19422\end{array}$

$\begin{array}{llllll}\text { woxcar } & 1.05840 & -0.08517 & 0.02632 & 0.09982\end{array}$

MEDMAL $0.94113 \quad 0.05838 \quad 0.00222 \quad 0.10451$

$\begin{array}{lllllll}\text { OThL1A } & 0.52058 & 0.66175 & 0.01822 & 0.16178\end{array}$

SPELIA $0.73300 \quad 0.13660 \quad 0.13627-0.06073$

$\begin{array}{llllll}\text { PROL 1A } & 0.76355 & 0.20860 & 0.03330 & 0.07551\end{array}$ 
IABLE S. ESTIMATEO O-STATISTICS OF tHE RESIOUALS FOR AR(2,1) MOOEL

$$
k=3 \quad k=6 \quad k=5 \quad k=6 \quad k=7
$$

HOWFAN $1.98996 \quad 2.16336 \quad 3.36277 \quad 3.89976 \quad 3.99259$ Paval $5.67318 \quad 6.5237 \quad 6.83369 \quad 8.01369 \quad 8.49348$ convit $8.26154 \quad 9.46501 \quad 13.1095723 .5606628 .98261$ conval 15.91527 19.07583 22.34264 24.80556 27.03102 woxcon 17.42113 26.60334 25.35317 32.6700135 .69136 MEOMLL 3.48611 4.3468 8.9303013 .5787614 .25841 $\begin{array}{llllllll}\text { OTHLIA } & 6.28978 & 5.97255 & 6.36765 & 6.62106 & 6.62712\end{array}$ SPELIA $1.91596 \quad 2.26386 \quad 3.28078 \quad 3.30667 \quad 3.31895$ PROL IA 10.602711 .6267611 .5625011 .6372411 .65731

$$
\text { ACCIOENI YEAR }=83
$$

$k=3 \quad K=6 \quad K=6$

MONFM $2.762512 .05360 \quad 3.21604 \quad 4.18011$ PRVAUT $3.03098 \quad 4.00322 \quad 4.60045 \quad 4.81416$ $\begin{array}{lllll}\text { conut } 5.97649 & 7.44506 & 7.64307 & 23.31011\end{array}$ convil 0.5422412 .3672716 .5681017 .93802 voxcon $7.9806315 .33981 \quad 16.52810 \quad 17.33435$ MEDMAL 20.139625 .5252930 .4772838 .19085 OTMLIA $8.11671 \quad 8.283211 .3678211 .42570$ SPELIA $1.47905 \quad 1.87616 \quad 3.32353 \quad 3.71316$ Pro. 1A 10.67283 17.39252 19.15464 22.12186

$$
\begin{aligned}
& \text { ACCIDEWT YEAR = } 84 \text { ACCIDENT YEAR }-85 \\
& K=3 \quad K=6 \quad k=5 \quad K=3 \quad K=6
\end{aligned}
$$

$\begin{array}{llllll}\text { HOWFAM } 2.05900 & 6.76390 & 7.06356 & 5.50869 & 5.96703\end{array}$ $\begin{array}{llllllll}\text { PRVAUT } 2.03376 & 5.38396 & 7.92933 & 7.46222 & 8.40334\end{array}$

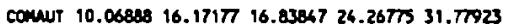
conar 18.55787 19.17965 19.7039515 .6377016 .71569 woxed $15.3147716 .47673 \quad 16.96446 \quad 6.42555 \quad 6.96612$ $\begin{array}{lllllll}\text { MEDMUL } & 1.54353 & 2.58499 & 13.71380 & 1.85397 & 2.21131\end{array}$ OTKLIA $5.51735 \quad 6.19361 \quad 7.76043 \quad 11.9004813 .22891$ SPELIA $8.40713 \quad 10.13026$ 23.01675 $3.15066 \quad 3.23195$ PROL IA 18.54066 25.60756 36.80326 11.1856013 .16175 
TABLE 5. ESTIMATED D-STATISTICS OF THE RESIDUALS FCQ AR(2, 1) MOOEL

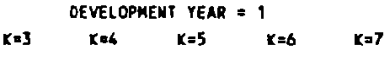

HONFAM 16.63397 19.64255 20.59734 23.40826 24.88186 PRVAUT 11.98079 15.6623821 .1013326 .9956027 .26196 conivT 8.08051 11.72902 16.20662 31.7616536 .63307 convl 20.6317s 26.85926 30.6358032 .9066337 .20689 woxcon 16.93724 22.40653 23.9236025 .8260825 .96615 MEDMal 8.9603811 .6897112 .5796112 .9030913 .02912 OTHLIA 17.73336 22.70700 27.4861729.51769 33.16230 SPELIA 18.02518 18.9376019 .5360520 .2690520 .59256 PROLIA $7.84671 \quad 9.18015 \quad 9.98272 \quad 11.6429311 .87074$

OEVELCOMENT YEAR = 2

$K=3 \quad K=6 \quad K=5 \quad K=6$

HONFAM 12.6795615 .7267618 .3023232 .04126

PRvaut $13.09267 \quad 16.42352 \quad 20.7457422 .55493$

conut $7.63526 \quad 0.50123 \quad 11.62120 \quad 18.42212$

Convil 10.8021014 .6095816 .6383727 .08606

Loxcon 10.4559519 .0762723 .9903726 .13308

MEDXAL 16.61185 21.4513123 .2746524 .53169

OTHLIA 16.8079918 .6062519 .6852020 .20313

SPEL1A 16.71297 15.86508 18.1873319 .24093

PRoLla $0.0356311 .0370412 .33 m 712.70747$

$$
\begin{aligned}
& \text { DEVELOPMET YEAR - } 3 \text { DEVELCPHENT YEAR }=4 \\
& K=3 \quad k=6 \quad k=5 \quad k=3 \quad k=4
\end{aligned}
$$

MONFAN $12.59476 \quad 13.61527 \quad 13.83793 \quad 6.64678 \quad 11.21330$ PRVAUT 13.30962 18.26313 20.58350 13.25334 13.34350 conut 11.9057216 .9606720 .74827 .9580911 .02764 conve $16.9818218 .1660519 .30833 \quad 8.1643410 .32852$ $\begin{array}{lllll}\text { vercon } 6.89509 & 7.86669 & 0.11616 & 10.03875 \quad 10.80485\end{array}$ MEOMAL $6.6593313 .8064216 .30530 \quad 6.26661 \quad 0.74575$ OTMLIA 15.3680726 .1158728 .18779 10.07070 16.35889 $\begin{array}{lllllll}\text { SPELIA } & 7.65181 & 9.61350 & 11.73637 & 6.15198 & 6.24645\end{array}$ Pra. IA 15.55548 18.15833 $20.22100 \quad 6.75053 \quad 7.67302$ 
TABLE 6. PCAF OF THE ESTIMATED RESIDUALS fOR AR(2,1) MOOEL

RESIDUAL PARTIAL NUTOCORRELATIONS FOR AT 82

RESIDUAL PARTIAL AUTOCORRELATIONS FOR AT 83

15T LAG 2ND LAG JRO LAG LTH LAG STH LAG GTH LAG 1ST LAG 2ND LAG 3RO LAG GTH LAG STH LAG GTH LAG

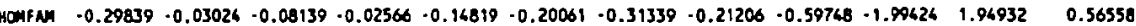
$\begin{array}{lllllllllllllllllllllllllll}\text { PRVAUT } & -0.35057 & -0.00372 & -0.00093 & -0.00169 & 0.00082 & 0.00181 & -0.38088 & -0.00887 & -0.00289 & -0.00790 & -0.00272 & 0.00433\end{array}$ $\begin{array}{lllllllllllllllll}\text { convit } & -0.1037 & 0.00114 & -0.00225 & -0.00254 & -0.00430 & -0.00256 & -0.30283 & 0.00347 & -0.00406 & -0.01270 & -0.00360 & -0.02637\end{array}$ $\begin{array}{lllllllllllllllllll}\text { convl } & 0.09390 & -0.01189 & -0.00157 & -0.00268 & -0.00151 & -0.00045 & -0.44897 & 0.00397 & -0.00569 & -0.00561 & -0.02227 & -0.00574\end{array}$

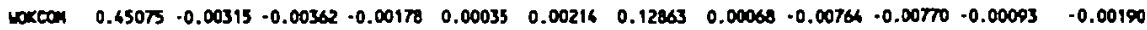

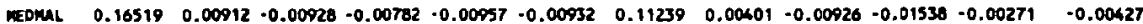
$\begin{array}{lllllllllllllllllll}\text { otkli } & -0.21331 & -0.03138 & -0.00047 & -0.01174 & -0.06263 & -0.01222 & -0.13467 & -0.03399 & -0.06090 & -0.06096 & -0.16086 & -0.12331\end{array}$ SPELIA $-0.12222 \cdot 0.09918-0.11554 \cdot 0.11675 \quad 0.02340 \quad 0.00631 \quad 0.15227 \quad 0.22705 \cdot 0.15534 \cdot 0.02263 \cdot 0.05877 \quad-0.06188$

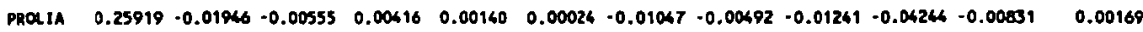

RESIOUAL PARTIAL AUTOCORELLATLOHS FOR AY Q

RESIOUAL PARTIAL AUTOCORRELATIONS FOR AY 85

15T LAG 2ID LAG 3R0 LAG GTH LAG 5TH LAG GTH LAG IST LAG 2ND LAG 3R0 LAG GTM LAG 5TH LAG GTH LAG HOAFAM $-0.005058 \quad-0.006 \cdot 0.01433 \quad-0.03493 \quad 0.014516 \cdot 0.01964 \cdot 0.11976 \quad-0.05905 \quad 0.040935 \quad 0.016009 \quad-0.0523 \quad-0.0090964$

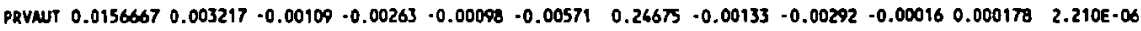

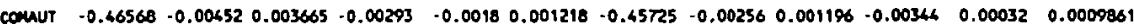

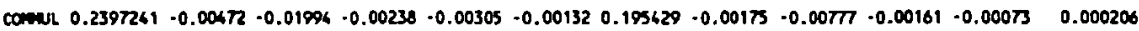

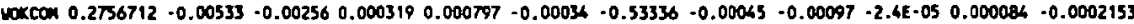

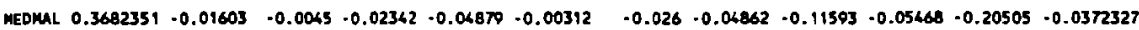
OIHLIA $0.0061007 \cdot 0.018460 .019313 \cdot 0.01696 \cdot 0.02119 \quad 0.003093 \cdot 0.61031 \cdot 0.00536 \cdot 0.00605 \cdot 0.00085 \quad 0.000095 \quad 0.0001095$

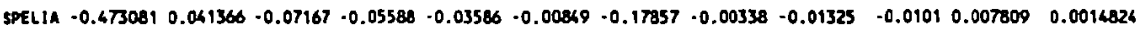

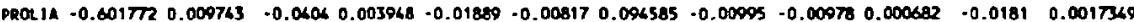

RESIDUAL PARTIAL NUTOCORELATIOAS FOA OY

RESIOUAL PATIIAL NUTOCOARELTIOAS FOR OY 2

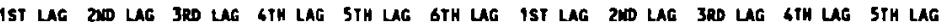
HOAFAM $0.10441-0.05122-0.00100 \quad 0.01980 \cdot 0.01004-0.0093 \quad 0.09371-0.01559-0.05582-0.01565-0.00559$ PRVAUT $=0.12470 \cdot 0.00017 \cdot 0.00012 \quad 0.00000 \cdot 0.00002 \quad 0.00002 \quad 0.44546 \cdot 0.00104 \cdot 0.00009 \cdot 0.00055 \cdot 0.00123$ cownt $-0.21823 \cdot 0.02537 \cdot 0.00582 \quad 0.01807 \quad 0.00780 \cdot 0.01841 \cdot 0.0 \% 15 \quad 0.01338 \cdot 0.01452 \cdot 0.00935 \cdot 0.01747$ conlt $-0.01338 \cdot 0.03375 \cdot 0.00120 \quad 0.00760 \cdot 0.00828 \cdot 0.00234 \cdot 0.30425 \cdot 0.02328 \cdot 0.07694 \quad 0.01252 \quad 0.01284$ waxcon $-0.15666 \cdot 0.01164 \cdot 0.00086 \quad 0.00692 \cdot 0.00051 \cdot 0.00156 \cdot 0.04033 \cdot 0.00734 \cdot 0.00633 \quad 0.00939 \cdot 0.00130$ MEDNAL $-0.30151-0.08300-0.37307-0.68592-0.84343-4.46305 \quad 0.06496-0.02510 \cdot 0.01709-0.00599-0.00269$ $\begin{array}{lllllllllllllllllll}\text { OTHLIA } & 0.00015 & -0.39626 & 0.05815 & -0.11715 & -0.05636 & 0.01327 & -0.11265 & -0.00791 & -0.00253 & -0.00697 & 0.00876\end{array}$ SPEL1A $-0.06512-0.06156-0.01675 \quad 0.00651 \quad 0.02518-0.00397-0.01628 \cdot 0.06230-0.08022 \quad 0.03488 \quad 0.00849$

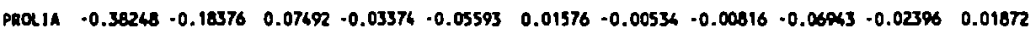
18T LAG 2AD LAG 3RD LAG LTH LAG 5TH LAG GTH LAG IST LAG 2ID LAG 3RD LAG GTH LAG STH LAG

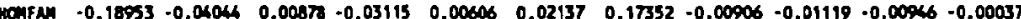
pavaut $0.44993-0.00274-0.00413-0.00426-0.00055 \quad 0.00079 \quad 0.53043 \quad-0.00635 \cdot 0.00715 \cdot 0.00195 \quad-0.00060$

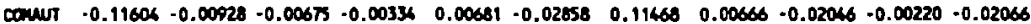
conit $\quad-0.12782 \cdot 0.01971-0.00771 \quad 0.00835 \quad 0.01224 \cdot 0.00631 \cdot 0.11636 \cdot 0.01955 \cdot 0.02103 \quad 0.00670 \quad 0.01672$

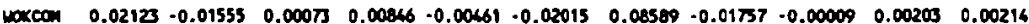
wonk $0.25400 \cdot 0.02553 \cdot 0.03058 \cdot 0.01050 \quad 0.00558 \quad 0.01747 \quad 0.26950 \cdot 0.03012 \cdot 0.01741 \cdot 0.01940 \quad 0.01161$ $\begin{array}{llllllllllllllll}\text { othLIA } & 0.04945 & -0.01640 & -0.01122 & -0.01399 & 0.01167 & 0.00525 & 0.04172 & -0.05498 & -0.01581 & 0.01260 & 0.00645\end{array}$

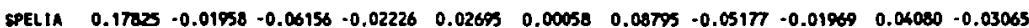

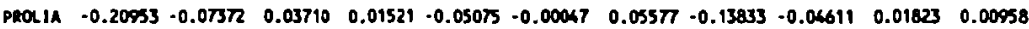

STH UAE 0.00912 0.00190 $-0.00040$ $-0.00424$ $-0.01867$ -0.0018 . $-0.00000$ $-0.04013$ $-0.0057$ 
TABLE 7. ESTIMATED COEFFICENTS SOR AR(3,1) MOOEL

1ST YEAR 2HD YEAR 3RD YEAR IST YEAR

AY LAC AY LAG AY LAG OY LAG CONST

$\begin{array}{llllll}\text { MORFNM } & 0.02596 & 0.67760 & 0.66232 & 0.05052 & 0.17660\end{array}$

PRVAut $0.522110 .39406 \quad 0.04301-0.001610 .18837$

$\begin{array}{lllllll}\text { convi } & 0.96376 & -0.03759 & 0.05602 & 0.01672 & 0.10371\end{array}$

$\begin{array}{lllllllll}\text { conul } & 0.57237 & -0.15216 & 0.35489 & 0.23526 & -0.14156\end{array}$

$\begin{array}{llllllllll}\text { uxxcan } 1.06169 & -0.72865 & 0.69056 & -0.00487 & 0.23127\end{array}$

$\begin{array}{llllllllllll}\text { REDUL } & 0.96271 & 0.06672 & -0.01021 & 0.00256 & 0.10270\end{array}$

$\begin{array}{lllllll}\text { OTHLIA } & 0.32960 & 0.24380 & 0.41688 & 0.01021 & 0.24196\end{array}$

$\begin{array}{lllllllll}\text { SPELIA } & 0.67767 & -0.16442 & 0.39012 & 0.09879 & -0.00733\end{array}$

$\begin{array}{llllllllllll}\text { PROLIA } 0.69942 & -0.20058 & 0.47181 & 0.03626 & 0.11847\end{array}$ 
TAELE B. ESTIMATED O-STATISTICS OF TKE RESIDUALS fOQ AR(3,1) MOOEL

\begin{tabular}{|c|c|c|c|c|c|}
\hline & \multicolumn{4}{|c|}{ ACCIOENT YEAR : 82} \\
\hline & & $k=4$ & $x=5$ & $K=6$ & $x \rightarrow 7$ \\
\hline HONF AM & 1.09961 & 2.06500 & 2.97566 & 3.63561 & 3.46336 \\
\hline PRVAut & 5.56150 & 6.32262 & 6.64156 & 7.64102 & 8.05060 \\
\hline conut & 0.16380 & 9.29051 & 12.72606 & 22.87711 & 28.23220 \\
\hline conevit & 16.53650 & 19.75038 & 23.49269 & 25.95561 & 28.53064 \\
\hline & 19.11617 & 26.39896 & 25.27048 & 32.04011 & 33.56336 \\
\hline MEONAL & 3.69878 & 4.3607 & 0.96902 & 13.59271 & 14.28166 \\
\hline OTHLIA & 4.18413 & 5.60641 & 6.06382 & 6.31699 & 6.32329 \\
\hline SPELIA & 1.80286 & 2.09206 & 2.94262 & 3.02819 & 3.02900 \\
\hline PROLIA & 10.78075 & 11.56971 & 11.72503 & 11.82286 & 611.84372 \\
\hline
\end{tabular}

$$
\text { ACCIOENT TEAR }=\mathrm{BS}
$$

$$
K=3 \quad K=4 \quad K=5 \quad K=6
$$

HONFAM $3.00390 \quad 3.19160 \quad 3.47231 \quad 4.55810$ PRVAUT $3.02613 \quad 4.02696 \quad 4.63506 \quad 6.86792$

conutit $6.022567 .66375 \quad 7.6084023 .16026$

CONEL $7.7686610 .01261 \quad 13.87038 \quad 15.65627$

woxcon 8.2153115 .5675816 .7002916 .93862 MEDMAL 20.1642825 .5181230 .483739 .23301

$\begin{array}{lllllll}\text { OTHLIA } 7.27898 & 7.38832 & 10.29606 & 10.34060\end{array}$ SPELIA $1.66465 \quad 1.97280 \quad 3.36948 \quad 3.68350$ PROLIA 10.85263 17.76777 19.67225 22.63624

$$
\begin{aligned}
& \text { ACCIDEMT YEAR = } 84 \text { ACCIDENT TEAR = OS } \\
& x=3 \quad x=4 \quad x=5 \quad x=3 \quad x=6
\end{aligned}
$$

HOATAM $3.47006 \quad 11.40593 \quad 12.13779 \quad 2.39762 \quad 3.26036$ PRVAUT 2.77706 $5.20330 \quad 7.77981 \quad 7.33106 \quad 8.51191$ convi $9.3222815 .0725315 .79316 \quad 21.9706130 .34663$ convl 18.38219 $18.77972 \quad 19.25384 \quad 9.07117 \quad 10.22135$ $\begin{array}{lllllll}\text { wexcon } 7.16027 & 7.49055 & 7.90569 & 4.38527 & 5.29526\end{array}$ $\begin{array}{lllllll}\text { MEDML } 1.5667 \mathrm{~T} & 2.59282 & 13.76100 & 1.85622 & 2.21259\end{array}$ $\begin{array}{lllllll}\text { OTHL1A } & 7.29723 & 7.87348 & 9.76389 & 10.06132 & 10.63447\end{array}$ SPELIA $10.78656 \quad 13.38671 \quad 25.73312 \quad 6.81150 \quad 7.12185$ PROLIA 18.87935 $26.4267034 .61267 \quad 6.16343 \quad 6.58304$ 
TABLE 8. ESTIMAIED O-STATISTICS OF THE RESIDUALS FO AR(3,1) MOEL

DEVELOPMEHT VEAR = 1
$\mathbf{K}=\mathbf{3}$
$\mathbf{K}=\mathbf{6}$
$K=5 \quad X=6$
$x=7$

HOWFAN $17.8268721 .0461323 .07158 \quad 24.98393 \quad 27.15608$ PRVAUT 11.03701 16.3988819 .4978023 .0758824 .94225 cowns $6.57246 \quad 8.72126 \quad 13.0338028 .9153935 .40280$ convl 20.0335625 .7146931 .4685133 .4219630 .33703 woxcon $8.08916 \quad 9.10016 \quad 9.9358311 .5110311 .76411$ MEDWL $8.7449111 .6840312 .3536112 .67248 \quad 12.79706$ orMLIA $10.3893514 .33840 \quad 17.3166517 .8298818 .07093$ SPELIA 18.52091 19.4609720 .0365320 .4629020 .93029 PROLIA 15.27199 19.91718 21.19592 23.37152 26.59059

OEVELOPHENT YEAR $=2$

KnJ Ka4 Kas K.6

HOMFAM 10.8849311 .9395312 .2117820 .84216

PRVAuT 13.52875 17.50895 21.4808423 .50739

conut $7.98087 \quad 9.0503711 .0546717 .58706$

conir 11.9066315 .0175616 .3328429 .18738

voxcon $8.21686 \quad 16.1053926 .6960620 .53668$

MEDMLL 16.5676621 .6363723 .2661524 .55222

ОтнL1A 16.5062615 .8889517 .1268917 .76156

SPELIA 10.2215111 .5223914 .6990216 .72538

PROL1A $0.03733 \quad 9.61659 \quad 10.63513 \quad 11.23291$

$$
\begin{aligned}
& \text { OEVELOPNET YEAR - } 3 \text { DEVELCPMENT TEAR - } 4 \\
& K=3 \quad K=6 \quad x=5 \quad K=3 \quad K=6
\end{aligned}
$$

HOHFN 9.6457910 .3697510 .5074211 .0466218 .18216 PRVRUT 13.h2957 18.21212 20.00778 12.42276 12.60368 $\begin{array}{lllllll}\text { contr } 11.80267 & 15.14643 & 21.79389 & 6.32948 & 8.06215\end{array}$ convl 16.69330 17.66970 20.20201 12.39557 13.46746 uxcon 12.1845619 .4655722 .849065 .1004110 .99673 $\begin{array}{lllllllll}\text { NEDMAL } 6.65069 & 13.76803 & 16.19655 & 6.22486 & 8.72807\end{array}$ OIMLIA 15.37184 $26.1334626 .06879 \quad 8.66626 \quad 10.23055$ SPELIA $16.8518610 .3479623 .94580 \quad 4.27263 \quad 4.47297$ Prolla is.87020 18.06519 19.863795 .087025 .69904 
TABLE 9. PCAF OF THE ESTIMTED RESIOUALS FOQ AR(3,1) MCOEL.

RESIOUAL PARTIAL MUTOCORRELATIONS FOR AY 82

RESIDUAL PARTIAL AUTOCORRELATIONS FOR AY BS IST LAG 2ND LAG 3RD LAG GIM LAG STH LAG 6TH LAG 15T LAG 2NO LAG 3RO LAG GTH LAG 5TH LAG GIM LAG

HOAFAN $-0.26716-0.05608 \cdot 0.09823 \cdot 0.03268-0.15005 \cdot 0.19583 \cdot 0.36105-0.16823-0.28186-0.5693 \quad-1.00730 \quad 165$ $\begin{array}{llllllllllllll}\text { pevart } & -0.35392 & -0.000376 & -0.00087 & -0.00155 & 0.00078 & 0.00171 & -0.37976 & -0.00642 & -0.00266 & -0.00779 & -0.00259\end{array}$ conavt $-0.10556 \quad 0.00113-0.00222 \quad-0.00252-0.00426-0.00256-0.30055 \quad 0.00354-0.00612-0.01273-0.00370$ comir $0.07346 \cdot 0.00944-0.00113-0.00155-0.00185 \cdot 0.00011 \cdot-0.43716 \quad 0.00220-0.00590 \cdot 0.00456-0.02300$ $\begin{array}{llllllllllllll}\text { woxcon } & 0.42938 & -0.00243 & -0.00268 & -0.00118 & 0.00076 & 0.00140 & 0.21136 & -0.00119 & -0.00926 & -0.00818 & -0.00126\end{array}$

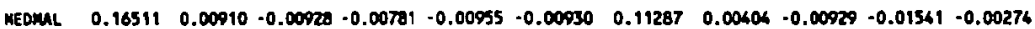

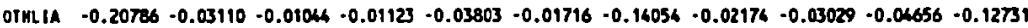
SPELIA $=0.06205=0.09696=0.12202-0.09324 \quad 0.03265 \quad 0.00158 \quad 0.14931 \quad 0.20989-0.13631-0.02612-0.06189$ $\begin{array}{llllllllllllllllllll}\text { PROL } & 0.26115 & -0.01899 & -0.00559 & 0.00428 & 0.00163 & 0.00018 & -0.02790 & -0.00369 & -0.01099 & -0.04032 & -0.00852\end{array}$

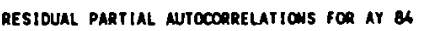
IST LAG 2N0 LAG 320 LAG 4TH LAG 5TH LAG 6TH LAG 15T LAG 2ND LAG 3RO LAG 4TH LAG 5TH LAG

MOMFAN $\begin{array}{llllllllllll}0.0779 & -0.00496 & -0.01208 & -0.02316 & 0.00795 & -0.00433 & -0.17042 & -0.03738 & 0.02303 & 0.01861 & -0.04912\end{array}$ PRVAUT $0.01303 \quad 0.00306 \cdot 0.00103 \cdot 0.00246 \cdot 0.00097 \cdot 0.00552 \quad 0.26761 \cdot 0.00172 \cdot 0.00316 \cdot 0.00026 \quad 0.00028$ conut $=0.48487-0.00436 \quad 0.00393 \cdot 0.00318 \cdot 0.00176 \quad 0.00115 \cdot 0.42019 \cdot 0.00236 \quad 0.00080 \cdot 0.00406 \quad 0.00055$ CONWL $0.25694 \cdot 0.01070 \cdot 0.00853 \cdot 0.00239 \cdot 0.00244 \cdot 0.00148 \cdot 0.07603 \quad 0.00781 \cdot 0.00963 \cdot 0.00349 \cdot 0.00504$ $\begin{array}{lllllllllllllllll}\operatorname{vox} \operatorname{con} & 0.01346 & -0.00281 & -0.00161 & 0.00052 & 0.00050 & 0.00004 & -0.10101 & 0.00206 & -0.00480 & -0.00246 & -0.00149\end{array}$ MEDML $0.36923 \cdot 0.01605 \cdot 0.00475 \cdot 0.02360 \cdot 0.04905 \cdot 0.00309 \cdot 0.02576 \cdot 0.06798 \cdot 0.11721 \cdot 0.05509 \cdot 0.20639$ OTHLIA $\quad-0.02931-0.01409 \quad 0.01604 \cdot 0.01398 \cdot 0.01551 \quad 0.00166 \cdot 0.04590 \quad-0.00408 \cdot 0.01676 \quad 0.00086 \cdot 0.00257$

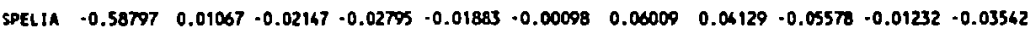

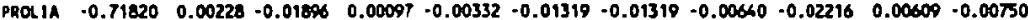

DESIOUAL PARTIAL AUTOCORELATIONS FOR OY 1

RESIOUAL PARTIAL NTOCORELATIOAS FOR OY 2

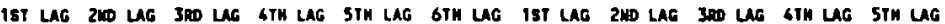
HOAFAM $0.23170-0.05296 \cdot 0.00917 \quad 0.01946-0.00627-0.01357 \quad 0.10000-0.01616-0.10801-0.00309-0.0077$ $\begin{array}{lllllllllllllllll}\text { PRVAUT } & -0.16311 & -0.00015 & -0.00013 & 0.00008 & -0.00002 & 0.00002 & 0.36253 & -0.00109 & -0.00092 & -0.00055 & -0.00025\end{array}$ $\begin{array}{llllllllllllllll}\text { cond } & -0.23192 & -0.02296 & -0.00552 & 0.01620 & 0.00802 & -0.01801 & -0.18665 & 0.00064 & -0.00556 & -0.00842 & -0.01235\end{array}$

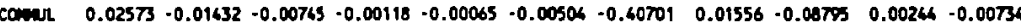

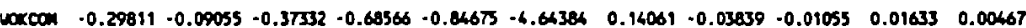
MEDHAL $-0.12728-0.02112-0.01536-0.00478 \quad 0.01650-0.00126 \cdot 0.00312 \quad 0.01149-0.04696 \quad 0.00255+0.01053$ OTILIA $\quad-0.50265 \cdot 0.00245 \cdot 0.00075 \quad 0.00121 \cdot 0.00105 \quad 0.00052 \cdot 0.51547 \cdot 0.00022 \cdot 0.00031 \quad 0.00116 \cdot 0.00069$ SPELIA $0.23052 \cdot 0.25837 \cdot 0.00921 \cdot 0.05346 \cdot 0.06886 \quad 0.01160 \cdot 0.11998 \cdot 0.00037 \cdot 0.00311 \cdot 0.00269 \quad 0.00265$ PROLIA $\cdot 0.38036 \cdot 0.05289 \quad 0.08004 \cdot 0.07761 \cdot 0.06781 \quad 0.01103 \cdot 0.02004 \cdot 0.00532 \cdot 0.06729 \cdot 0.06119 \quad 0.01674$

$-0.00044$

$-0.00015$

.0 .03708

$-0.00033$

0.00085

$-0.00051$

GTH LAG 0.03960 0.00051 0.00811 0.0436 ? $-0.0057$ 0.00084 0.00018 $-0.00151$ $0.007 \% 5$

RESIOUAL PARTIAL MTOCORRELATIONS FOR or 3

RESIDUAL PARTIAL AUTOCORRELATIONS FOA OY 6

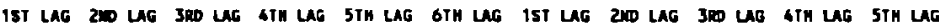
$\begin{array}{llllllllllllllll}0.10623 & -0.02 \% 46 & -0.00545 & -0.00213 & 0.00105 & 0.00075 & 0.49432 & -0.00582 & -0.00626 & -0.00158 & 0.0019\end{array}$ $\begin{array}{llllllllllll}0.25605 & -0.00364 & -0.00390 & -0.00250 & 0.00136 & 0.00258 & 0.27579 & -0.00612 & -0.00625 & 0.00164 & 0.00180\end{array}$ $=0.26976 \cdot 0.01230 \cdot 0.01730 \cdot 0.00502 \quad 0.01743 \cdot 0.00279 \cdot 0.05460 \cdot 0.00942 \cdot 0.01159 \quad 0.00530 \cdot 0.00062$ $\begin{array}{llllllllllll}-0.02071 & -0.00495 & -0.00726 & -0.00020 & 0.00301 & 0.00026 & 0.19221 & -0.01643 & -0.00646 & 0.00501 & 0.00242\end{array}$ $\begin{array}{llllllllllllll}0.19226 & -0.00518 & -0.01352 & -0.00255 & 0.00337 & 0.00103 & 0.01502 & -0.01277 & 0.00102 & -0.01046 & -0.00261\end{array}$ $\begin{array}{lllllllllllll}0.17799 & -0.01470 & -0.02706 & -0.00846 & 0.01132 & -0.00330 & 0.06160 & -0.02958 & -0.02602 & 0.01337 & -0.00176\end{array}$

$\begin{array}{lllllllllllllll}\text { OTKLIA } & -0.40906 & -0.00269 & 0.00018 & -0.00629 & 0.00166 & 0.00011 & -0.19610 & -0.00397 & -0.00276 & -0.01209 & 0.00510\end{array}$

PRa 14 $-0.42933-0.01915 \quad 0.01781-0.00325-0.01107-0.00225 \quad 0.21993-0.02346-0.04364-0.00565-0.01262$

6TH UA 0.00023 $-0.00055$ $-0.00000$ $-0.00062$ $-0.00022$ 0.00002 0.00139 0.00015 0.00146 


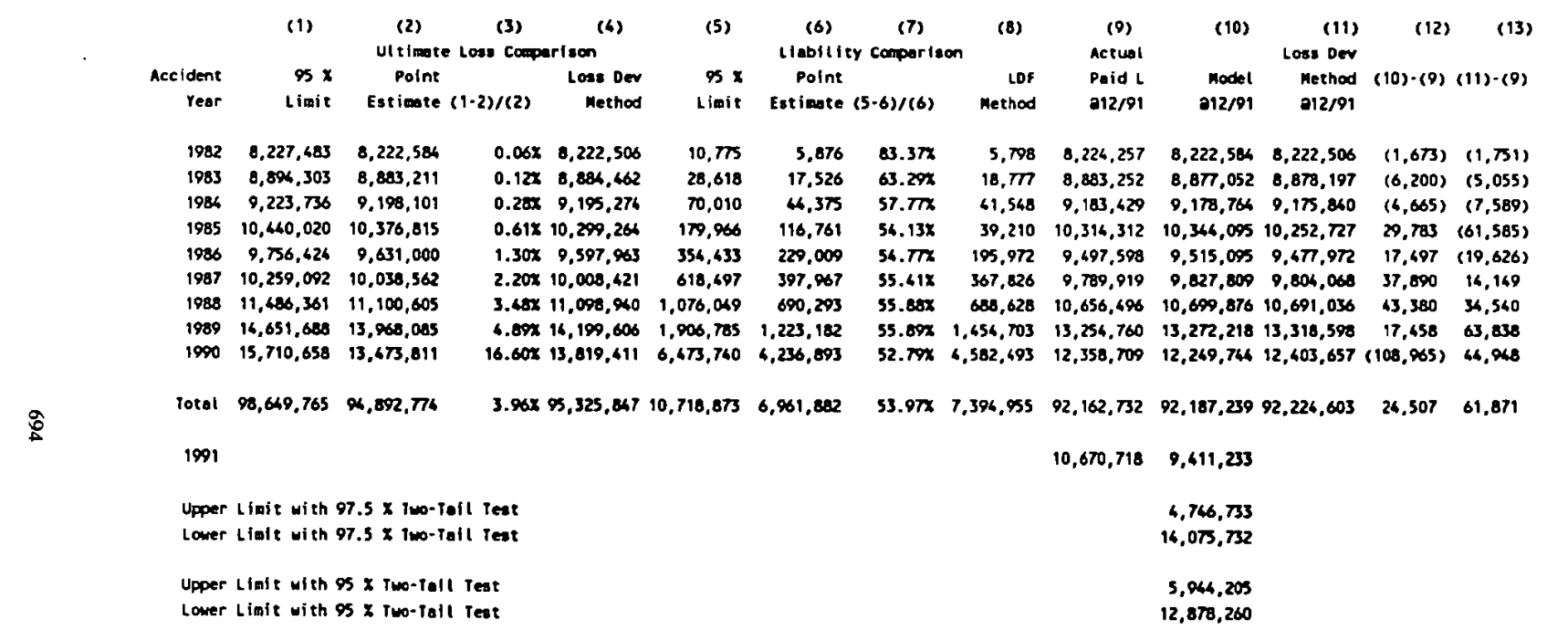




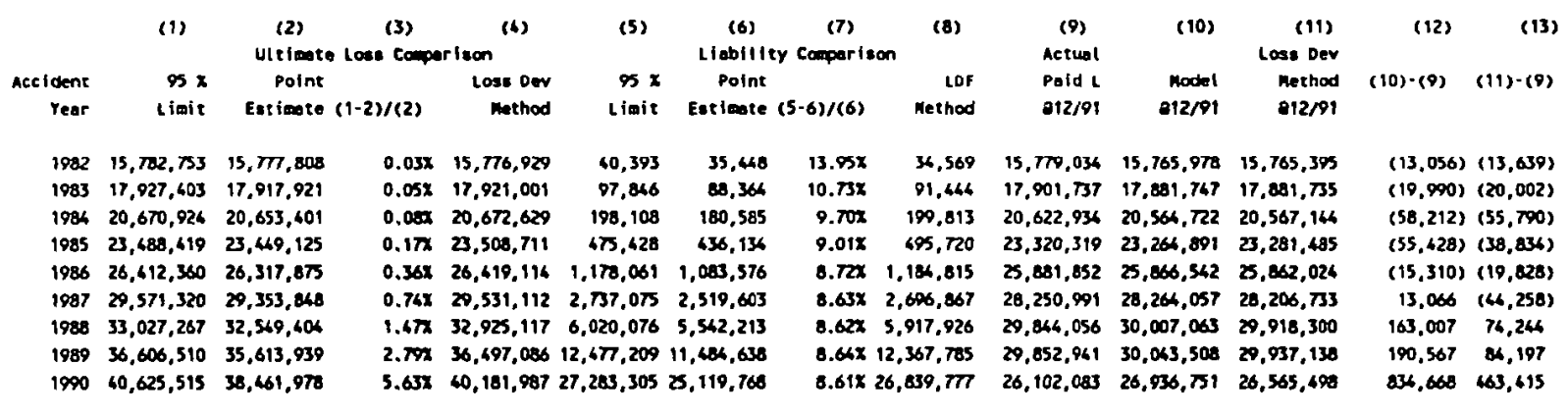

Totel $244,112,471240,095,290$

$1.67 \times 263,433,64650,507,50146,490,329$

$8.64 \times 49,028,716 \quad 217,555,947218,595,259217,905,451$

$1,039.312 \quad 429,504$

1991

Upper Limit wlth $97.5 \times$ Two-Tell Teet tower Lialt with $97.5 \times$ Two-7all teet

Upper Limit with $95 \times$ iwo-iall Teat Laver Lifilt with os $x$ Two-Toll Teal

\section{$13,360,803 \quad 16,876,262$}

$13,482,096$

$15,996,073$

$13,758,411$ 


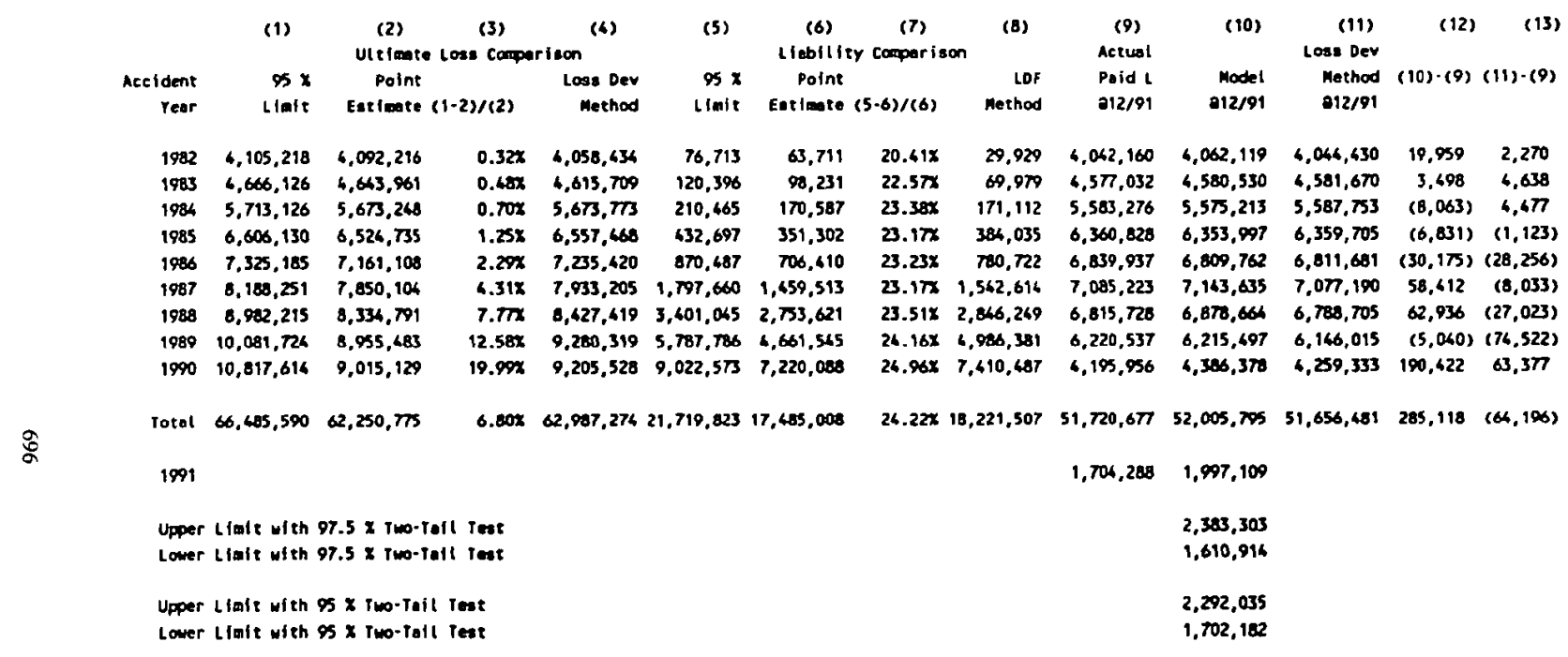




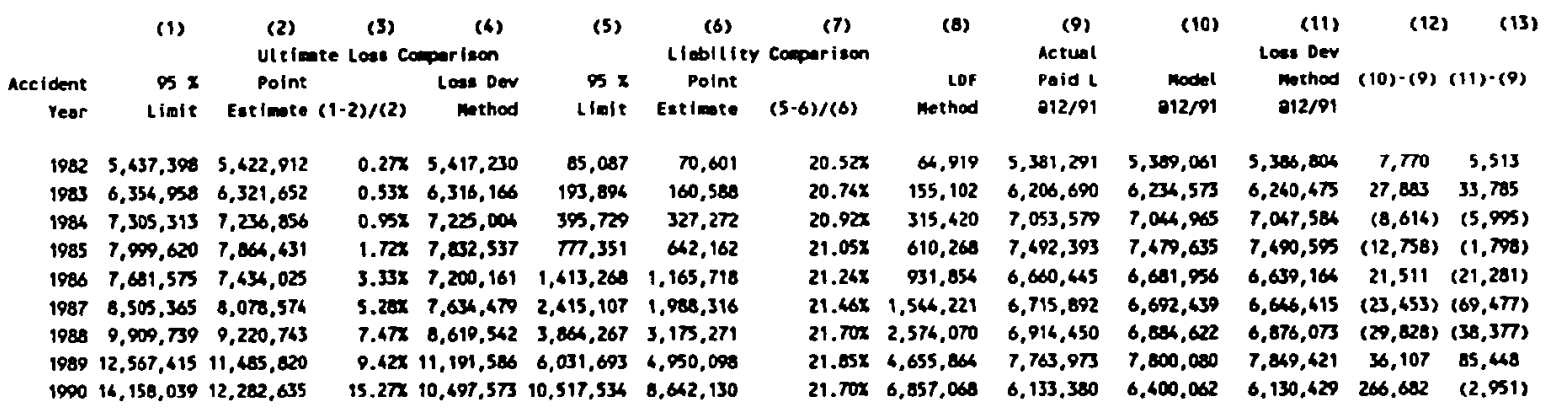

Total $7,919,422 \pi, 347,467 \quad 6.07 \times 71,934,27925,693,93021,122,155$

1991

Upper Lialt with $97.5 \times$ Two-Toll Teet Lover Linit with $97.5 \times$ Two-Tall Test

Upper Lialt with $95 \times$ two-Tall teat Lower Llait with $98 \times$ Two-Tall teat
$21.04 \times 17,708,707 \quad 00,322,093 \quad 60,607,392 \quad 60,306,060 \quad 205,290 \quad(15,133)$

$3,906,165 \quad 4,000,413$

$4,860,506$

$3,300,321$

$4.676,27$

$3,464,550$ 


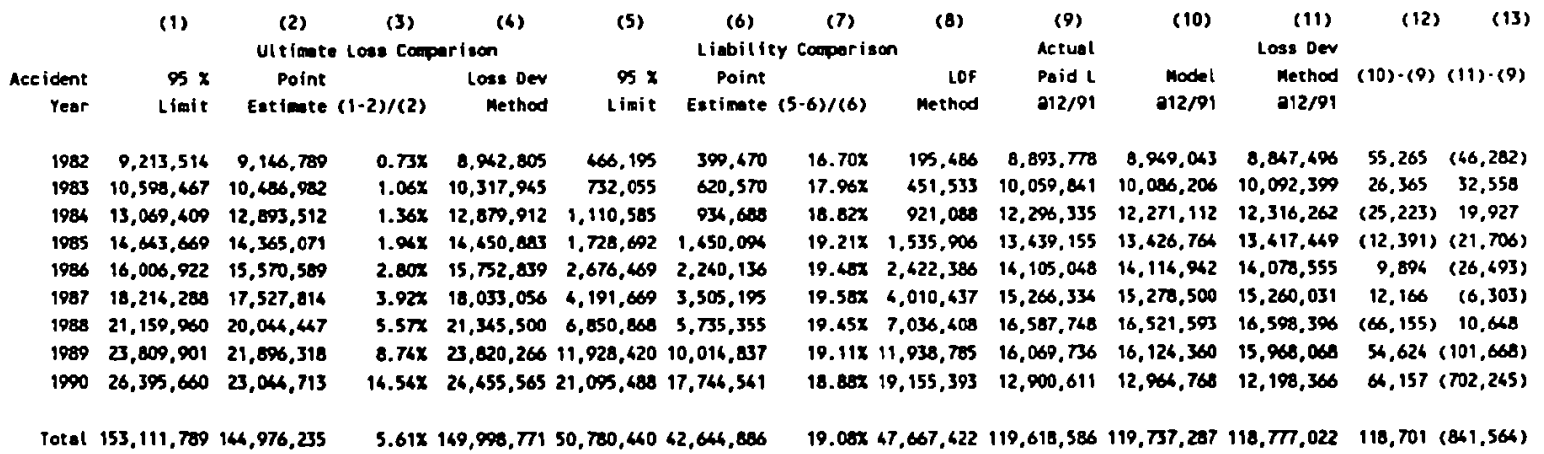

1901

Upper Lialt with $97.5 \times$ two-Tall Teat coner Limle with $97.5 \times$ ino-Tull Teat

Upper Lialt with os $x$ Two-Tall Teat Lower Linlt with $95 \times$ Two-Tall Teat
$5,608,600 \quad 0,066,709$

$6,947,791$

$5,165,628$

$6,737,861$

$5,355,558$ 


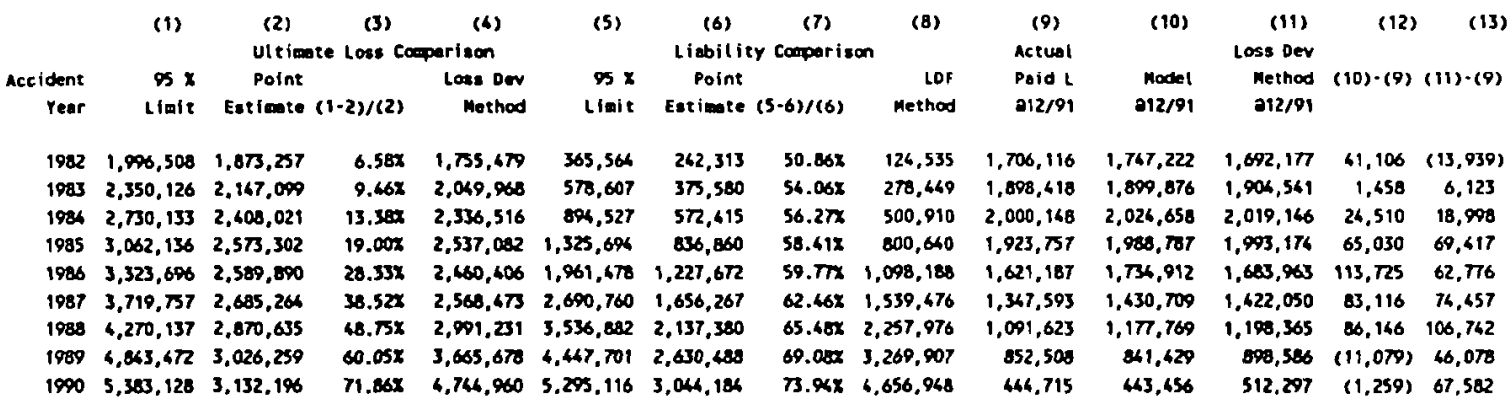

Fotal $31,679,09323,305,923 \quad 35.93 x \quad 85,109,792 \quad 21,096,329 \quad 12,725,159 \quad 65.81 \times 14,527,028 \quad 12,806,065 \quad 13,288,018 \quad 13,326,299 \quad 402,733 \quad 430,236$

1991

$97,720 \quad 99,978$

Upper Lifalt with 97.5 $\approx$ Tw-7oll Test

140,610

Lover Liait ut th $97.5 \times$ ino-rafl rest

59.530

Upper Liwit with $95 \times$ Two.Tall tes

130,260

Laver Liait with $95 \times$ iwo-Tall Test

69,687 


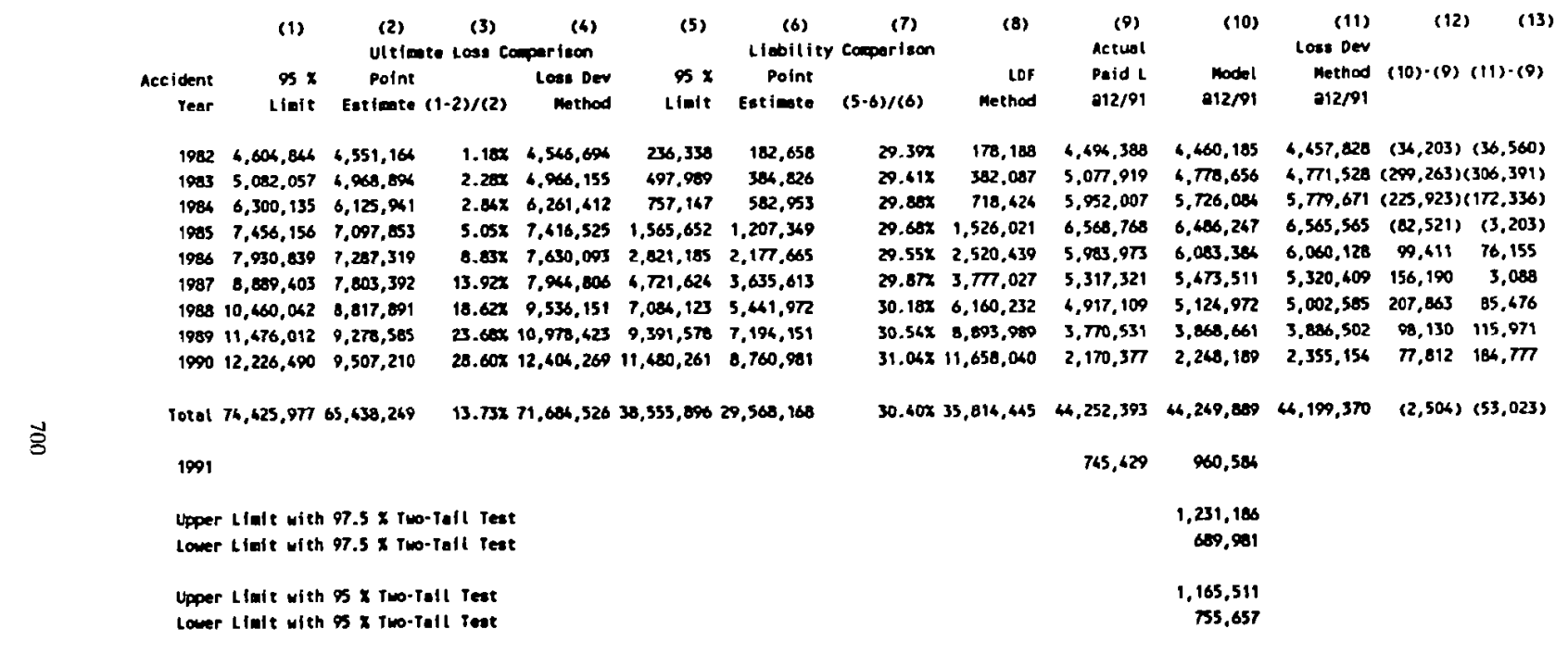




\begin{tabular}{|c|c|c|c|c|c|c|c|c|c|c|c|c|c|}
\hline \multirow[b]{2}{*}{$\begin{array}{l}\text { Lecident } \\
\text { resor }\end{array}$} & \multirow{2}{*}{$\begin{array}{c}\text { (1) } \\
95 x \\
\text { tieit }\end{array}$} & \multirow{2}{*}{$\begin{array}{l}\text { (2) } \\
\text { Uitime } \\
\text { Point } \\
\text { timoste C }\end{array}$} & \multirow{2}{*}{$\begin{array}{l}\text { (3) } \\
\text { (coses co } \\
0.2) /(2)\end{array}$} & \multirow{2}{*}{$\begin{array}{c}\text { (4) } \\
\text { xporison } \\
\text { Losis ow } \\
\text { nethod }\end{array}$} & \multirow{2}{*}{$\begin{array}{l}\text { (5) } \\
95 x \\
\text { Liait }\end{array}$} & \multirow{2}{*}{\multicolumn{2}{|c|}{$\begin{array}{c}(6) \quad(7) \\
\text { Listlity cooporison } \\
\text { Point } \\
\text { Estimate }(5-6) /(6)\end{array}$}} & \multirow{3}{*}{$\begin{array}{r}\text { (8) } \\
\text { Lor } \\
\text { Method } \\
2,760\end{array}$} & \multirow{3}{*}{$\begin{array}{c}(9) \\
\text { actuol } \\
\text { Peld L } \\
\text { ग12/91 } \\
1,124,673\end{array}$} & \multirow{3}{*}{$\begin{array}{r}(10) \\
\text { model } \\
\text { D12/91 } \\
1,124,848\end{array}$} & \multirow{3}{*}{$\begin{array}{c}\text { (11) } \\
\text { Loese on } \\
\text { Method } \\
\text { a12/91 } \\
1,123,263\end{array}$} & \multirow{2}{*}{\multicolumn{2}{|c|}{$\begin{array}{c}(12) \\
(10) \cdot(9)(11)-(9)\end{array}$}} \\
\hline & & & & & & & & & & & & & \\
\hline 1982 & $1,129,276$ & $1,126,76$ & $0.22 a$ & 1,724, & 7,87 & 5,3 & & & & & & 173 & \\
\hline 1983 & $1,279,008$ & $1,276,97$ & $0.38 x$ & $1,27,515$ & 16,624 & 9.751 & $49.97 \pi$ & 7.290 & $1,273.497$ & $1,269,260$ & $1,269,364$ & $(4,229)$ & \\
\hline & & & & & & & & 0 & & & & & \\
\hline 1985 & $1,382,886$ & 1.357 & $1.80 x$ & 1,356, & 76,656 & 69,695 & $0.23 x$ & 6,585 & & $1,332,671$ & $3,333,631$ & 5,568 & \\
\hline 1986 & $1,381,856$ & & & & & & & & & & & $(6,962)$ & \\
\hline & & & $6.05 x$ & & & & & & & & & & \\
\hline 1980 & $1,803,736$ & 1 & $9.87 x$ & & & & & & & & 6,276 & $(13,298)$ & \\
\hline & & & & & & & & & & & & 21,506 & \\
\hline 199 & & (w. & $37.7 \Delta x$ & & 3398 & & $51.66 x$ & 050,580 & $1,102,659$ & $1,090,503$ & $1,031,030$ & & \\
\hline
\end{tabular}

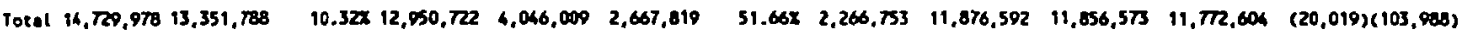

1991

Lpper Lialit with $97.5 \times$ Two-Tufl Test Laver LInit with $97.5 \times$ Two-Infl Tee

Upper Lialt with $95 \times$ two-Tell teat lower Llalt with $95 \times$ ino-toll ieat
$576,235 \quad 561,668$

778,117 305,219

718,289

365,067 


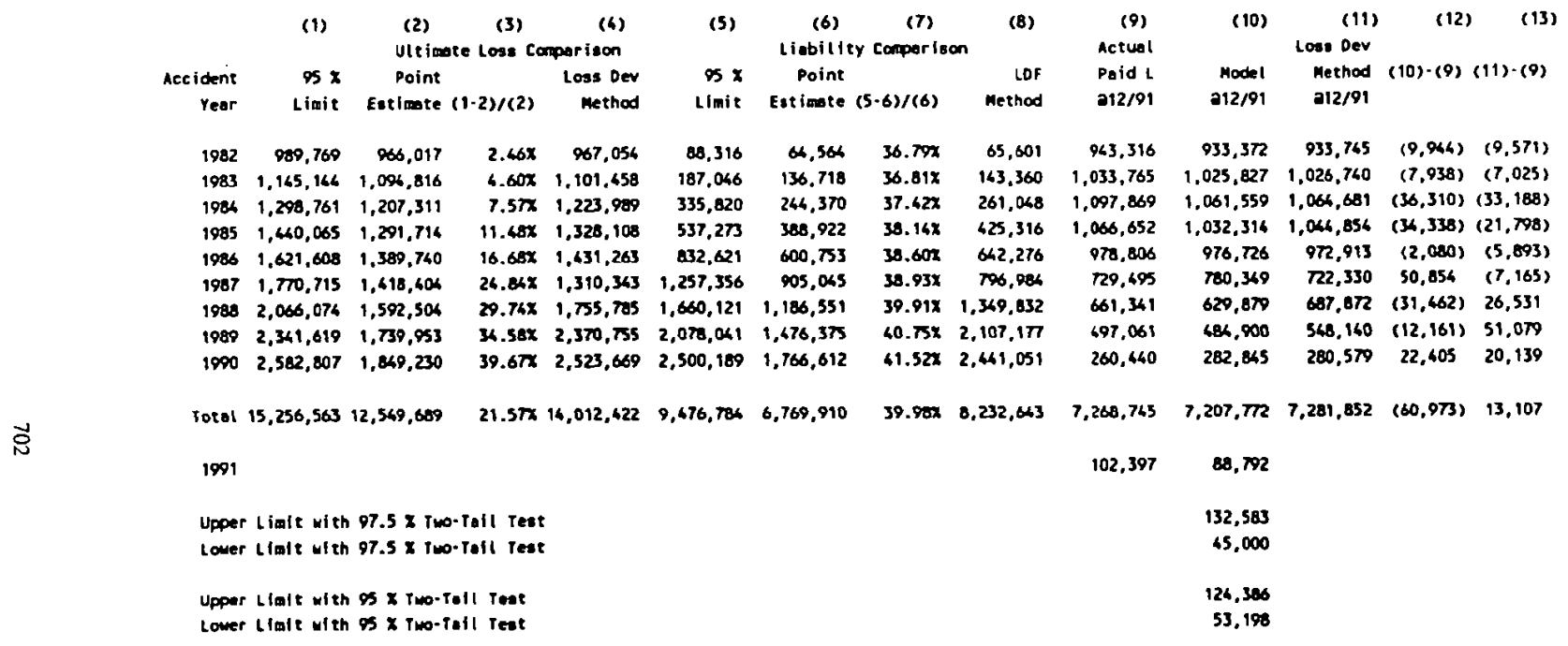




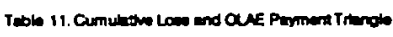

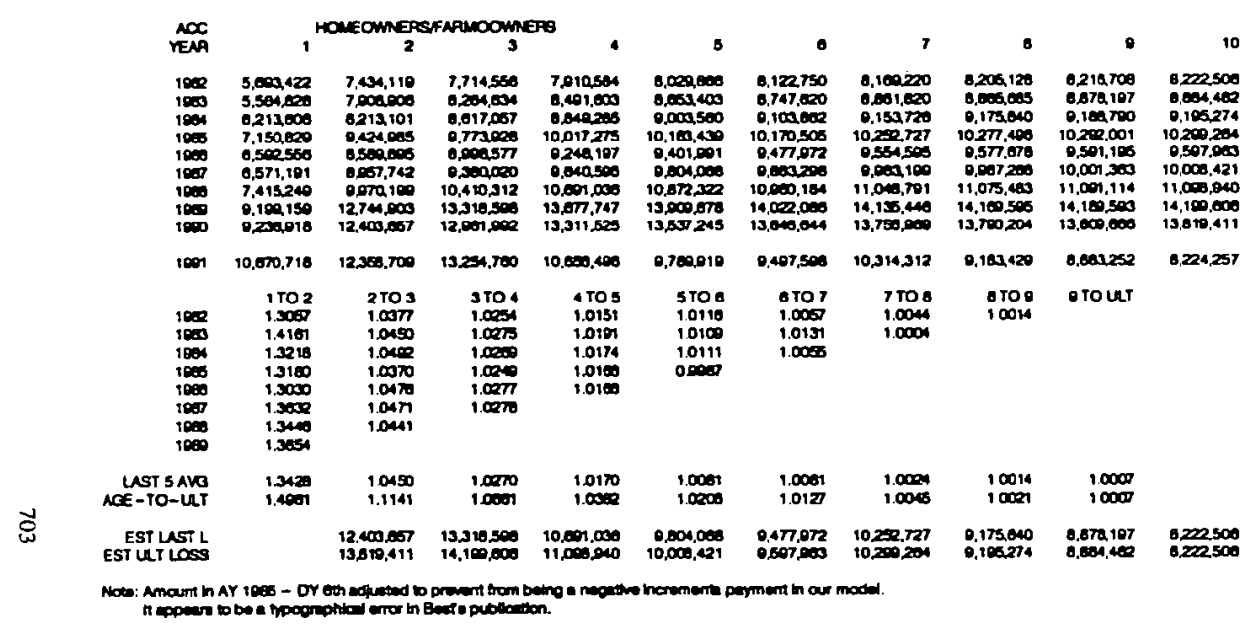




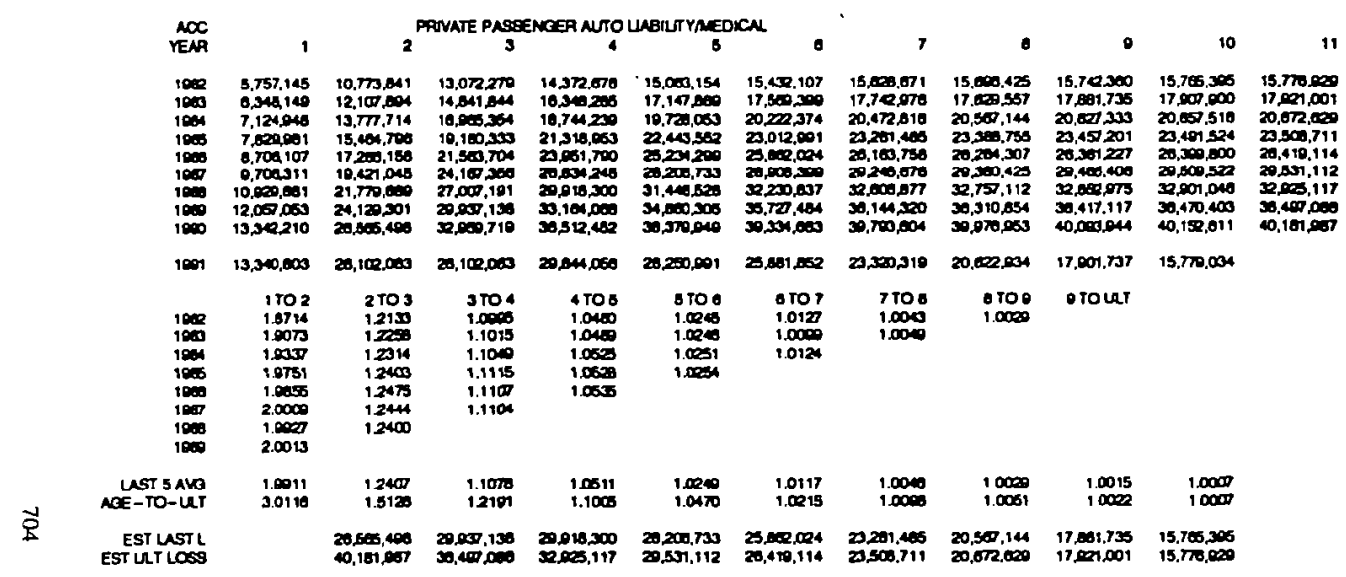




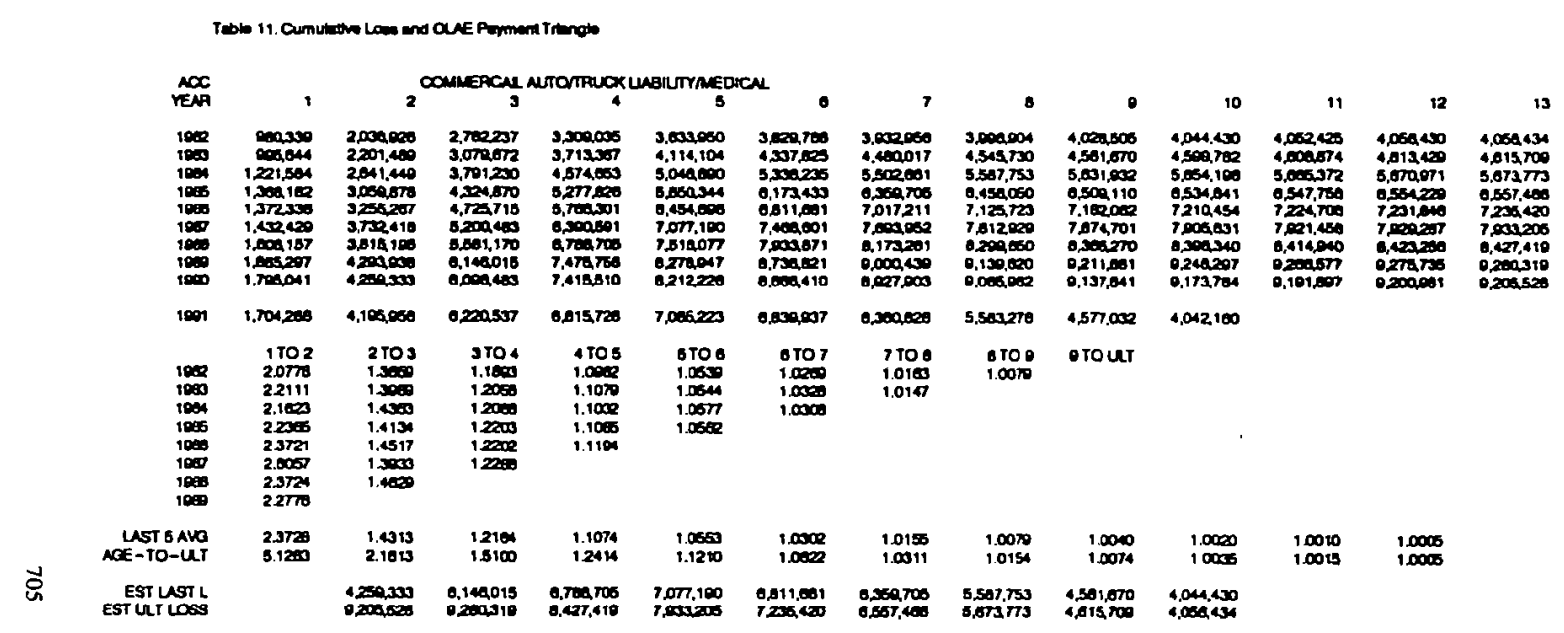




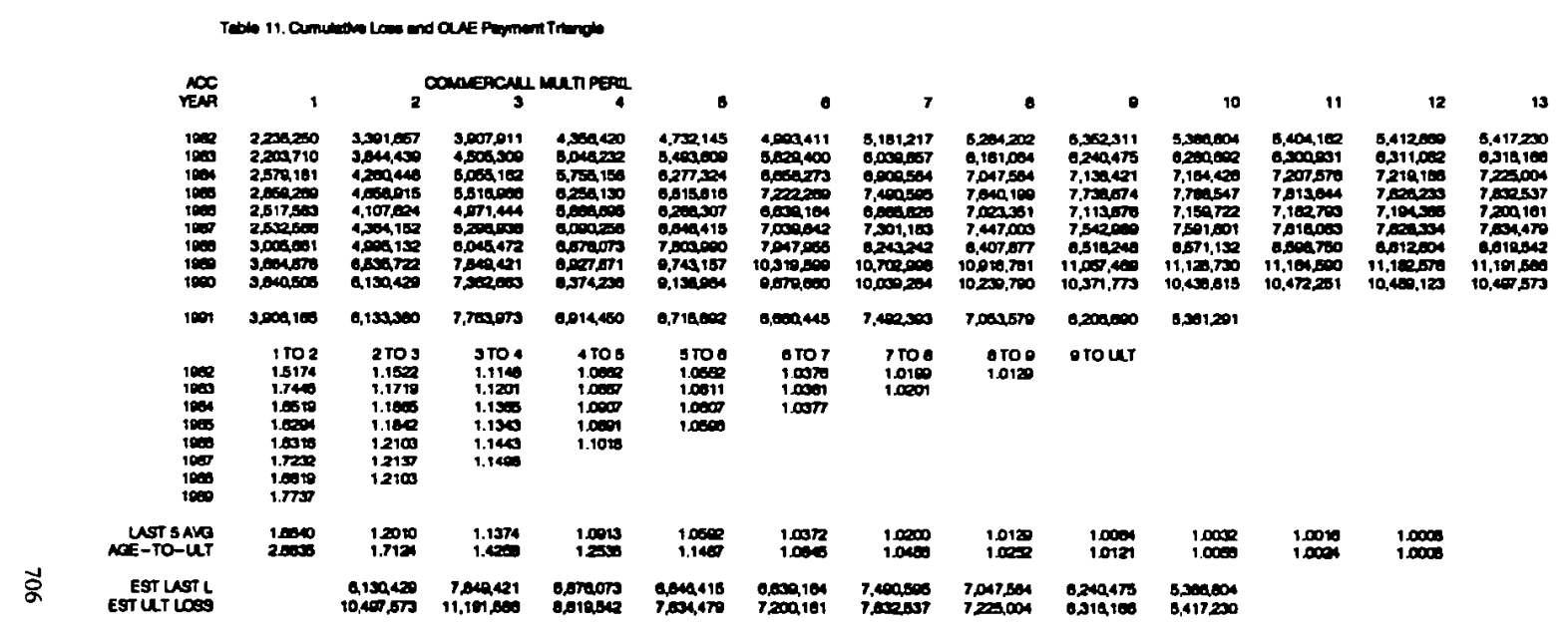




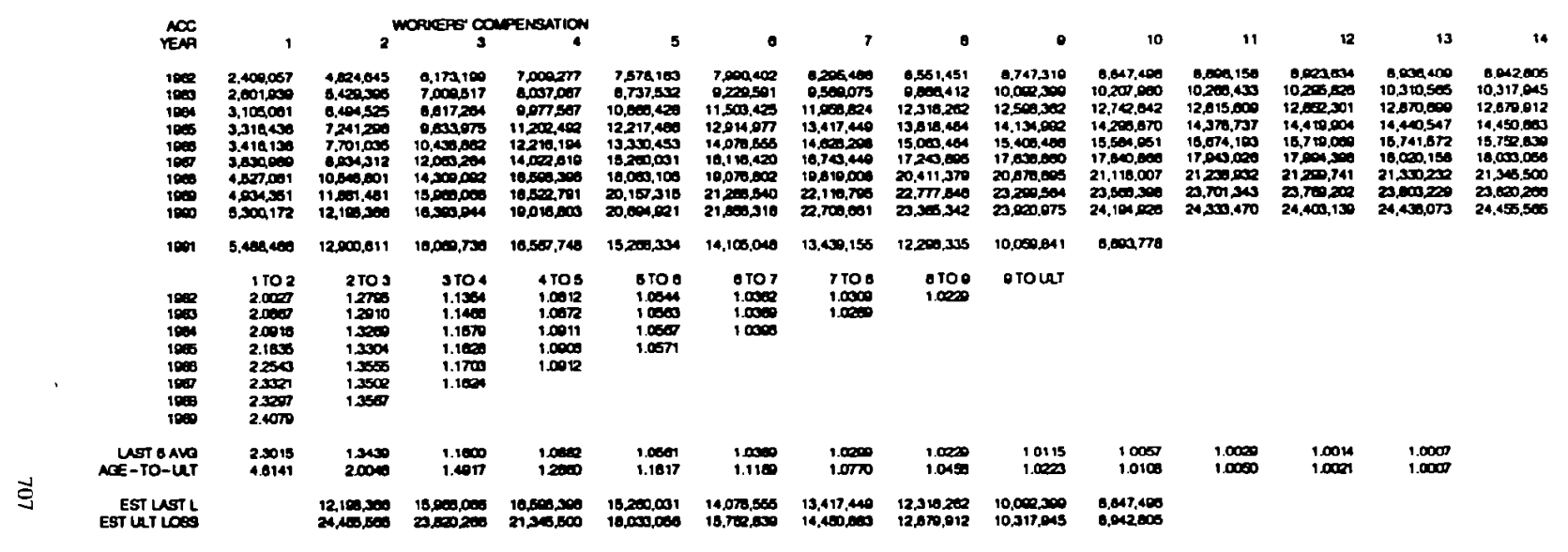




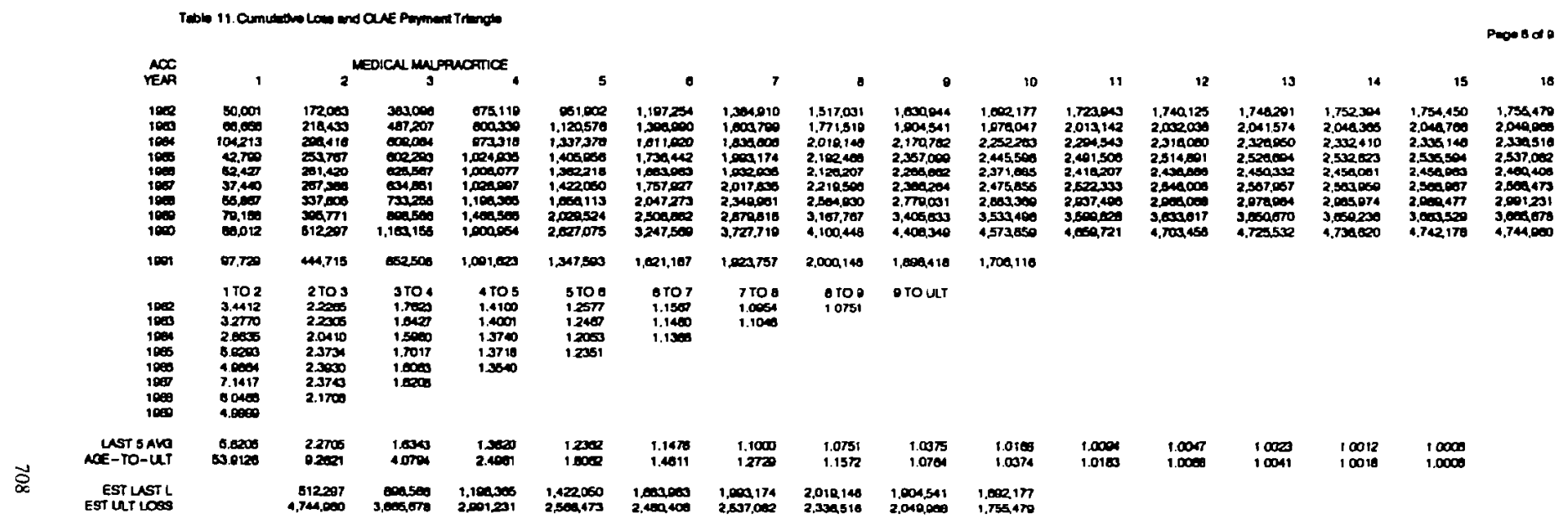




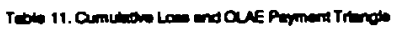

\begin{tabular}{|c|c|c|c|c|c|c|c|c|c|c|c|}
\hline$\underset{V \in A P}{A \infty C}$ & 1 & 2 & on whe & 4 & 5 & • & 7 & 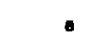 & - & 10 & 11 \\
\hline 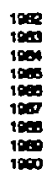 & 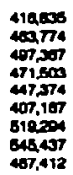 & 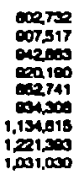 & 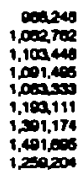 & 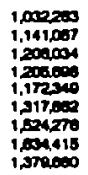 & 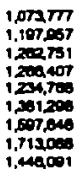 & 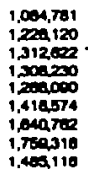 & 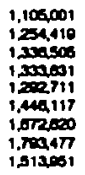 & 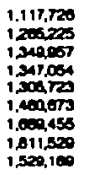 & 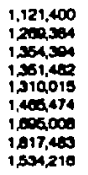 & 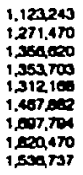 & 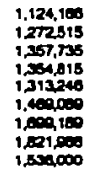 \\
\hline $\operatorname{lom}$ & sraxso & 1,102050 & $1,472,780$ & 1,3565800 & $1,200,000$ & 1,202500 & $1,207,123$ & $1,358,604$ & $1,272,497$ & $1,124,673$ & \\
\hline $\begin{array}{c}1000 \\
1000 \\
1000 \\
1000 \\
1000 \\
1000\end{array}$ & 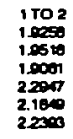 & $\begin{array}{l}2103 \\
12000 \\
1.1000 \\
1240 \\
12710 \\
12201\end{array}$ & $\begin{array}{l}3704 \\
1.0001 \\
1.100 \\
1.1000 \\
1.1000\end{array}$ & $\begin{array}{l}4 \text { TO B } \\
1.040 \\
10000 \\
1.0030\end{array}$ & $\begin{array}{l}5 \mathrm{~T} 00 \\
1.0100 \\
1.0000\end{array}$ & $\begin{array}{l}0 \text { T0 } 7 \\
1.0100\end{array}$ & $\begin{array}{l}710 \mathrm{a} \\
1.0115\end{array}$ & $\begin{array}{l}\text { S100 } \\
10000\end{array}$ & DTOULT & & \\
\hline & $\begin{array}{l}2.1158 \\
3.1554\end{array}$ & $\begin{array}{l}1.2213 \\
1.4011\end{array}$ & $\begin{array}{l}1,000 \\
1221\end{array}$ & $\begin{array}{l}1.0401 \\
1.11 \% 0\end{array}$ & $\begin{array}{l}1.02070 \\
1.0050\end{array}$ & $\begin{array}{l}1.0100 \\
1.0058\end{array}$ & $\begin{array}{l}1.0101 \\
1.0190\end{array}$ & $\begin{array}{l}1.0000 \\
1.0008\end{array}$ & $\begin{array}{l}10010 \\
1.0008\end{array}$ & $\begin{array}{l}10000 \\
1.0000\end{array}$ & \\
\hline & & 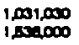 & $\begin{array}{l}1.401,000 \\
1,001,000\end{array}$ & $\begin{array}{l}1,624,270 \\
1 ; 009,110\end{array}$ & $\begin{array}{l}1,301,200 \\
1.400,0000\end{array}$ & $\begin{array}{l}1.2040000 \\
1.313240\end{array}$ & $\begin{array}{l}1,333001 \\
1,334,015\end{array}$ & $\begin{array}{l}1,340.067 \\
1,357.735\end{array}$ & $\begin{array}{l}1200,304 \\
1272515\end{array}$ & $\begin{array}{l}1.122,243 \\
i .124,100\end{array}$ & \\
\hline
\end{tabular}




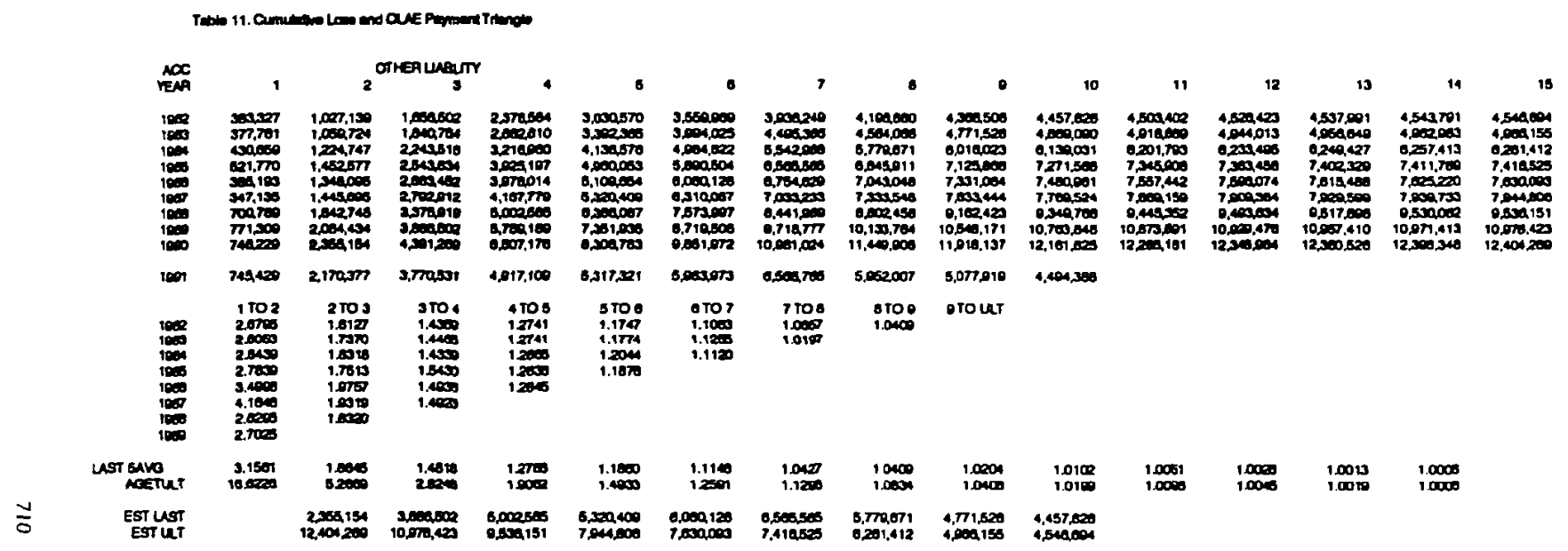




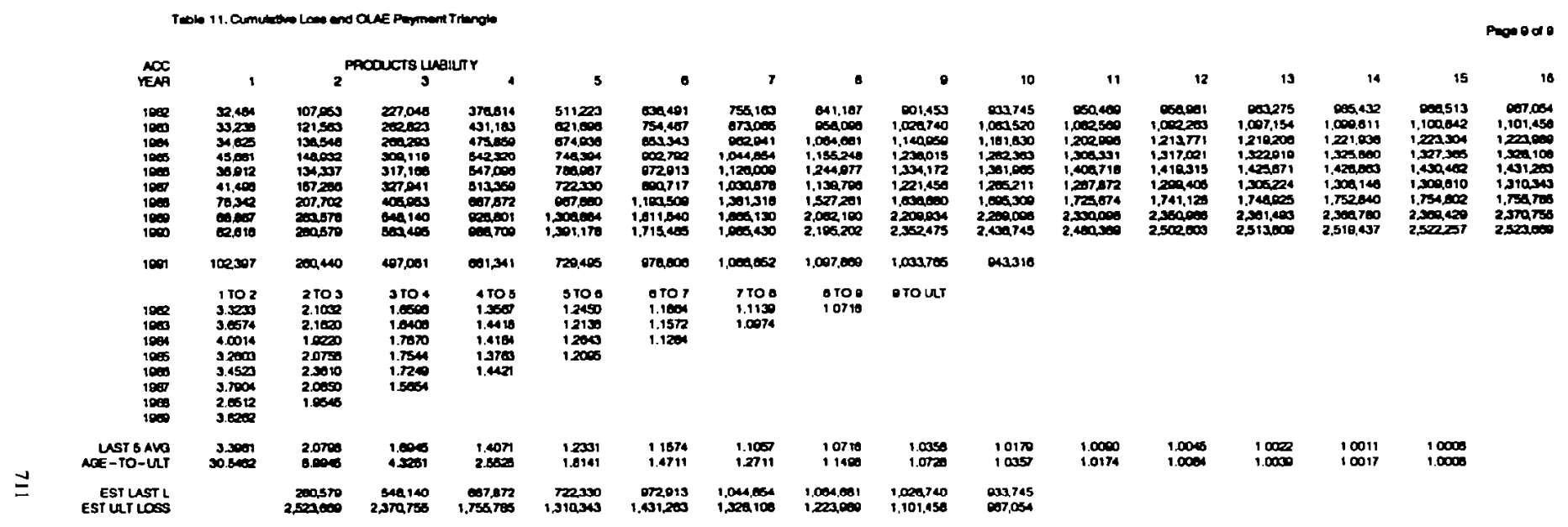


